\title{
Une visite présidentielle au village : Félix Faure dans le centre Bretagne le 8 août 1896
}

\section{Patrick Gourlay}

\section{(2) OpenEdition}

\section{Journals}

\section{Édition électronique}

URL : http://journals.openedition.org/abpo/2329

DOI : $10.4000 /$ abpo.2329

ISBN : 978-2-7535-1852-0

ISSN : 2108-6443

Éditeur

Presses universitaires de Rennes

Édition imprimée

Date de publication : 30 mars 2012

Pagination : 157-188

ISBN : 978-2-7535-1850-6

ISSN : 0399-0826

\section{Référence électronique}

Patrick Gourlay, « Une visite présidentielle au village : Félix Faure dans le centre Bretagne le 8 août

1896 », Annales de Bretagne et des Pays de l'Ouest [En ligne], 119-1 | 2012, mis en ligne le 30 mars 2014, consulté le 20 avril 2019. URL : http://journals.openedition.org/abpo/2329 ; DOI : 10.4000/abpo.2329 


\title{
Une visite présidentielle au village : Félix Faure dans le centre Bretagne le 8 août 1896
}

\author{
Patrick GouRlaY \\ Professeur d'histoire-géographie, doctorant \\ CRBC - Université Bretagne Occidentale
}

« Il y a fusion complète dans l'allégresse générale, [... ] la Bretagne, cette forteresse jadis inexpugnable de la monarchie a acclamé la République ${ }^{1}$. " Ainsi, le voyage de Félix Faure en Bretagne en 1896 avait-il été un révélateur de l'évolution politique de cette province encore perçue, au début de la Troisième République, comme une terre pittoresque, abritant une population fruste et non francophone, restée comme hors du temps un réduit chouan dominé par le château et le presbytère. Or, la venue du président au cœur même de cette Bretagne bretonnante et rurale allait permettre de mesurer, à l'aune de la fête républicaine et de la fraternité manifestée par les populations de ces petites communes, le niveau de l'attachement au régime républicain ou de l'éloignement de celui-ci.

Pour le pouvoir, la péninsule armoricaine restait encore une terre de mission dont il fallait poursuivre l'intégration à l'espace national. La visite présidentielle chercha ainsi à être un événement fédérateur favorisant l'unité républicaine au cœur de ces villages de basse Bretagne parés de tricolore. Cet événement, inédit à l'échelle de ces communes, permettait aussi, sans doute, à la population de s'approprier cette idée abstraite et lointaine qu'était la République. On peut donc penser qu'à côté de l'école et de l'armée qui furent les vecteurs essentiels d'une éducation citoyenne et politique, en profondeur, du monde paysan ${ }^{2}$, la politisation des campagnes s'est aussi faite à l'occasion de la visite officielle du président de la République au village.

1. Le Petit moniteur, 9 août 1896.

2. MARACHE, Corinne, «La responsabilisation politique du monde paysan dans les campagnes françaises (1830-1930) ", Parlemen[s], n 5, 2006, p. 75. 
Il est vrai que la Bretagne resta longtemps une terra incognita pour les chefs d'État ${ }^{3}$. François ${ }^{\text {er }}$ resta ainsi le seul monarque à avoir effectué (1518) un grand voyage de souveraineté, associant basse et haute Bretagne, jusqu'au voyage de Napoléon III en 1858. Avec la République, les visites présidentielles restèrent peu fréquentes jusqu'à " l'avènement gaulliste " qui fit de la péninsule armoricaine un lieu de déplacement privilégié du général ${ }^{4}$. La visite présidentielle, qui a toujours un but politique, porte en elle plusieurs enjeux : se donner à voir au peuple ${ }^{5}$, rencontrer les notables pour légitimer le pouvoir, parcourir l'hexagone pour travailler à l'unité nationale. C'est justement là que réside un des objectifs du voyage de Félix Faure en août 1896.

Si le très conservateur maréchal-président Mac Mahon avait, lui aussi, parcouru les départements de l'Ouest en août 1874, la venue du « PrésidentSoleil " représente le premier voyage réellement républicain en Bretagne. Parti du Havre, Félix Faure parcourt l'Ille-et-Vilaine, les Côtes-du-Nord, le Finistère, le Morbihan et la Mayenne, entre le 3 et le 15 août 1896. Après avoir passé les 6 et 7 août à Brest, Félix Faure entame le 8 une plongée dans la Bretagne intérieure en traversant le Finistère, de Brest à Quimper, avec huit arrêts : trois " arrêts-minutes " (Landerneau, Scrignac-Berrien, Locmaria-Huelgoat), un arrêt à Morlaix afin de changer de train, quatre arrêts avec réception officielle, vin d'honneur ou banquet (Carhaix, Châteauneuf-du-Faou, Pleyben, Châteaulin).

Le cortège présidentiel pénètre alors dans la Bretagne rurale et bretonnante et traverse des petits villages et des communes qui jamais, avant ni depuis, n'ont accueilli de duc, de monarque, d'empereur ou de président. On comprend dès lors que cette visite doive marquer la mémoire collective. Les journalistes ne s'y trompent pas, imaginant que cet épisode viendra nourrir l'histoire locale : " La population châteauneuvienne parlera longtemps de la visite présidentielle. Heureuse d'avoir fait au chef de l'État une réception aussi brillante que possible, elle gardera un inoubliable souvenir ${ }^{6}$. " D'autres soulignent que "l'impression a été profonde et le voyage présidentiel laissera pour longtemps sa trace marquée dans ces solitudes. Qui sait si l'imagination bretonne n'en fera pas des légendes ${ }^{7}$ ?"

Alors que la visite dans une grande ville est découpée elle-même en de très nombreuses séquences, la visite au village se concentre plus sur

3. GOURLAY, Patrick, Les Voyages des présidents de la République dans le Finistère (18742004). La mise en scène du pouvoir présidentiel en province, Master 2, université de Bretagne Occidentale, sous la direction de Christian Bougeard, 2004.

4. Gourlay, Patrick, "Les voyages du président de Gaulle en Bretagne. La France, la Bretagne et l'histoire ", Actes du colloque "L'Ouest dans les années 1968 ", Sciences Po Rennes, Université de Rennes 2, Université de Bretagne Occidentale, IUFM de Lyon, novembre 2010, à paraître aux Presses Universitaires de Rennes.

5. MARIOT, Nicolas, Bains de foule, les voyages présidentiels en province (1888-2002), Paris, Belin, 2006.

6. La dépêche de Brest, 13 août 1896.

7. Le Finistère, 11 août 1896. 
la rencontre avec les notables locaux et la population que sur la visite d'équipements ou de quartiers. L'exigence de contacts est d'ailleurs ferme de la part de l'Élysée. C'est le sens des consignes données au préfet par Louis Le Gall, directeur de cabinet de Félix Faure, lorsqu'il demande que les rencontres se fassent en plein air, à la vue de tous : « Le Président tient, [...] après avoir dit un mot aux maires des principales localités qu'il traverse, à se trouver immédiatement au contact de la population massée sur la place qui presque toujours précède la gare ${ }^{8}$."

\section{La mobilisation générale des élus et de la population}

\section{Création et rôle des commissions d'organisation}

L'organisation de la visite présidentielle préoccupe les municipalités d'autant plus qu'elles ne disposent que d'un mois pour prendre les mesures nécessaires. Les maires créent ainsi des commissions d'organisation et font voter les crédits indispensables à la réception du chef de l'État. De leur côté, les parlementaires les contactent afin de cerner les intentions des élus des communes visitées et de vérifier qu'ils sont prêts à dégager l'argent nécessaire permettant " de recevoir dignement le chef de l'État ${ }^{9}$ ". Si ce n'était pas le cas, le programme présidentiel en serait adapté.

À Carhaix, le conseil municipal s'est réuni le 10 juillet 1896 pour une session extraordinaire. Le maire, Ernest Bernard, annonce à son conseil qu'il a eu la confirmation de la venue de Félix Faure, par le commandant Moreau, officier de l'Élysée, venu la veille sur place pour préparer le voyage. Le conseil municipal décide d'employer les 3000 francs en excédant dans le budget 1896 à " recevoir dignement le Président de la République ${ }^{10}$ ». Est nommée ensuite une commission chargée de mettre en place les projets de décoration et d'animations. Si le commandant Moreau a mené début juillet une mission préparatoire, qui lui a permis de rencontrer les élus et de voir que le trajet en voiture de Carhaix à Châteaulin était réalisable, la presse relate l'entrevue accordée par Félix Faure à l'Élysée au sénateur Halléguen et aux députés Gourvil et Le Borgne venus l'entretenir du programme du voyage.

Les élus soulignent, comme ici ceux de Carhaix, qu'il s'agit bien d'un événement en soi : " Notre ville se prépare avec enthousiasme à recevoir la visite de M. Félix Faure, la première qui lui ait été faite par un chef de l'État. " L'enjeu est de taille et il faut tout faire pour être à la hauteur de ce rendezvous qui marquera l'histoire de la cité du Poher : "La journée du 8 août sera une date mémorable dans les annales de Carhaix ${ }^{11}$. " Le clou de cette journée sera le banquet populaire, l'occasion donnée de réunir aux Carhaisiens «nos braves amis des campagnes " afin d'exprimer ensemble leurs "sentiments

8. Arch. dép. du Finistère, 1 M 317, lettre de Louis Le Gall, directeur du Cabinet civil, au préfet du Finistère, 21 juin 1896.

9. Arch. mun. de Châteaulin, registre des délibérations du conseil municipal, 24 juin 1896.

10. Arch. mun. de Châteaulin, registre des délibérations du conseil municipal, 24 juin 1896.

11. Le Bas Breton, 18 juillet 1896. 
patriotiques $^{12}$ ". Il importe donc de mobiliser la population. Si les ressources de Carhaix ne permettent pas d'organiser un accueil du même type que dans les villes de Brest ou Quimper, tout sera fait pour que Félix Faure conserve de son passage " un souvenir heureux, celui d'une population toute entière unie pour honorer la République dans la personne de son principal représen$\operatorname{tant}^{13}$ ". À Châteaulin, le conseil municipal décide que " pour attirer le plus de monde possible, des fêtes auront lieu le jour du passage du président ${ }^{14}$ " en l'occurrence des courses de chevaux et des danses dans l'après midi.

Cet appel à la communion républicaine, à l'occasion de la visite présidentielle, est une constante. La lecture du Bas Breton, qui publie la lettre d'un Carhaisien, le vérifie : "Tous, pauvres comme riches, nous attendons avec impatience le chef de l'État auquel nous ferons le plus chaleureux accueil $^{15}$. " L'union républicaine est réelle car le vote des crédits s'est fait partout à l'unanimité.

Le cas de Pleyben permet de mesurer l'ampleur de l'implication qu'exige la visite présidentielle au village. Félix Faure doit rester une vingtaine de minutes dans cette commune de 5617 habitants. Une préparation méthodique occupe la commission d'organisation ${ }^{16}$ composée des élus municipaux et de personnalités désignées par le maire : le receveur des contributions directes, un conducteur des ponts et chaussées, l'instituteur, le percepteur, le juge de paix, le receveur de l'enregistrement, un avocat et un lieutenant-colonel à la retraite. On le voit clairement ici, à une époque où les services publics se développent dans les chefs-lieux de canton, les membres de cette commission choisis par le maire sont pour l'essentiel des fonctionnaires. Le maire entend sans doute s'appuyer ainsi sur des gens dévoués au régime et qui incarnent, au plan cantonal, la notabilité républicaine. Réunie le 5 juillet 1896, la commission relève les points à étudier : pavoiser certains chemins, décorer la mairie et repeindre les pièces pouvant être utilisées comme salle de réception, demander aux habitants de pavoiser, solliciter la fanfare de Pleyben et les binious du canton, demander à des cavaliers de se porter devant le cortège officiel en costumes, offrir un banquet et un cadeau au Président, demander la sonnerie des cloches.

Le 16 juillet 1896, cette commission d'organisation se divise en trois sous-commissions chargées de la décoration extérieure, de la décoration intérieure, du vin d'honneur et des cadeaux. Chacune dispose d'une partie des 1000 F votés le 12 juillet. La moitié de cette somme est allouée aux éléments de décoration extérieure : 60 mâts de 6 à 8 m (120 F), 60 oriflammes tricolores (102 F), 240 petits drapeaux (120 F), 60 écussons en bois aux

12. Ibidem.

13. Ibid.

14. Arch. mun. de Châteaulin, registre des délibérations du conseil municipal, 19 juillet 1896.

15. Le Bas Breton, 25 juillet 1896.

16. Arch. mun. de Pleyben, rapport de la commission d'organisation qui présente les dépenses et les actions menées à l'occasion de la visite de Félix Faure, 30 août 1896. 
couleurs nationales (120 F) et une guirlande (20 F). Les frais de décoration à l'intérieur de la mairie et de la salle de la justice de paix s'élèvent à $250 \mathrm{~F}$. Pour la réception, la commission commande pour $200 \mathrm{~F}$ de boissons et gâteaux : sont prévus au vin d'honneur du champagne, du vin rouge et du cidre (150 F), avec lesquels seront servis des gâteaux et des fruits (50 F). Le cadeau offert à Félix Faure est une photographie, reproduction au charbon, de l'église et du calvaire de Pleyben, encadrée, d'un coût de $100 \mathrm{~F}$, et un bouquet d'une valeur de $25 \mathrm{~F}$. S'il s'agit en priorité de faire ces achats auprès des artisans et commerçants du bourg, les membres de la commission n'hésitent pas à passer commande ailleurs : les mâts sont loués à Port-Launay, les travaux de décoration intérieure de la mairie sont confiés à un artisan de Châteaulin, les fruits sont fournis par un commerce brestois ainsi que la photographie remise au président, tandis que les écussons avec petits drapeaux pour les murs de la mairie sont achetés à Paris.

Le jeudi 7 août tout est en place : 56 mâts sont placés à $20 \mathrm{~m}$ de distance de chaque côté du chemin et 4 autres sont installés à l'entrée et à la sortie du territoire de la commune. Pleyben n'a pas suivi dans ce domaine Châteauneuf-du-Faou ou Carhaix qui ont fait ériger des arcs de triomphe pour marquer de manière symbolique l'espace communal. La moitié de la somme votée est consacrée à la transformation de l'espace urbain aux couleurs nationales : les chemins empruntés par le cortège officiel sont tous décorés de marqueurs républicains. Des sapins sont disposés en quinconce sur la place de l'église, les mâts sont reliés par des guirlandes et sont garnis de feuillage de la base au sommet. La mairie présente en façade des écussons, placés entre les fenêtres, des drapeaux au balcon, des guirlandes. De plus, les maisons du bourg ont été blanchies à la chaux, ornées de verdure, de drapeaux, et certaines d'écussons.

À Châteaulin, des pourparlers sont engagés très tôt avec une maison de Nantes spécialisée dans les feux d'artifice et la décoration. Comme ailleurs, les marqueurs républicains sont commandés : 130 mâts armés d'écussons, de trophées, de drapeaux, d'oriflammes le long de la voie parcourue par le cortège présidentiel. À ces mâts, s'ajoutent 50 drapeaux pour pavoiser les maisons. Là encore, le lieu de l'accueil doit subir des travaux : bois, briques, ferrures du marché couvert seront repeints à l'intérieur et à l'extérieur, car c'est là que le président sera reçu par le conseil municipal et que le vin d'honneur sera servi. De plus, un arc de triomphe sera érigé à l'entrée de la rue du marché. Cet ensemble est adopté à l'unanimité par le conseil qui " donne carte blanche à la commission d'organisation pour prendre sur les $5000 \mathrm{~F}$ déjà votés les fonds qui lui seront nécessaires afin que les choses soient faites convenablement ${ }^{17}$ ". La recherche d'efficacité explique sans doute cette délégation de pouvoir. Ce type d'événement est un marché pour les entreprises spécialisées : dans le cas de Châteaulin, sur l'ensemble des frais occasionnés, soit $3696,75 \mathrm{~F}$, on relève que l'entreprise nantaise, Petit Demaison, facture $2000 \mathrm{~F}$.

17. Ibidem. 
Figure 1 - La population en costume traditionnel ou endimanchée s'est massée dans une ville de Châteaulin pavoisée ${ }^{18}$

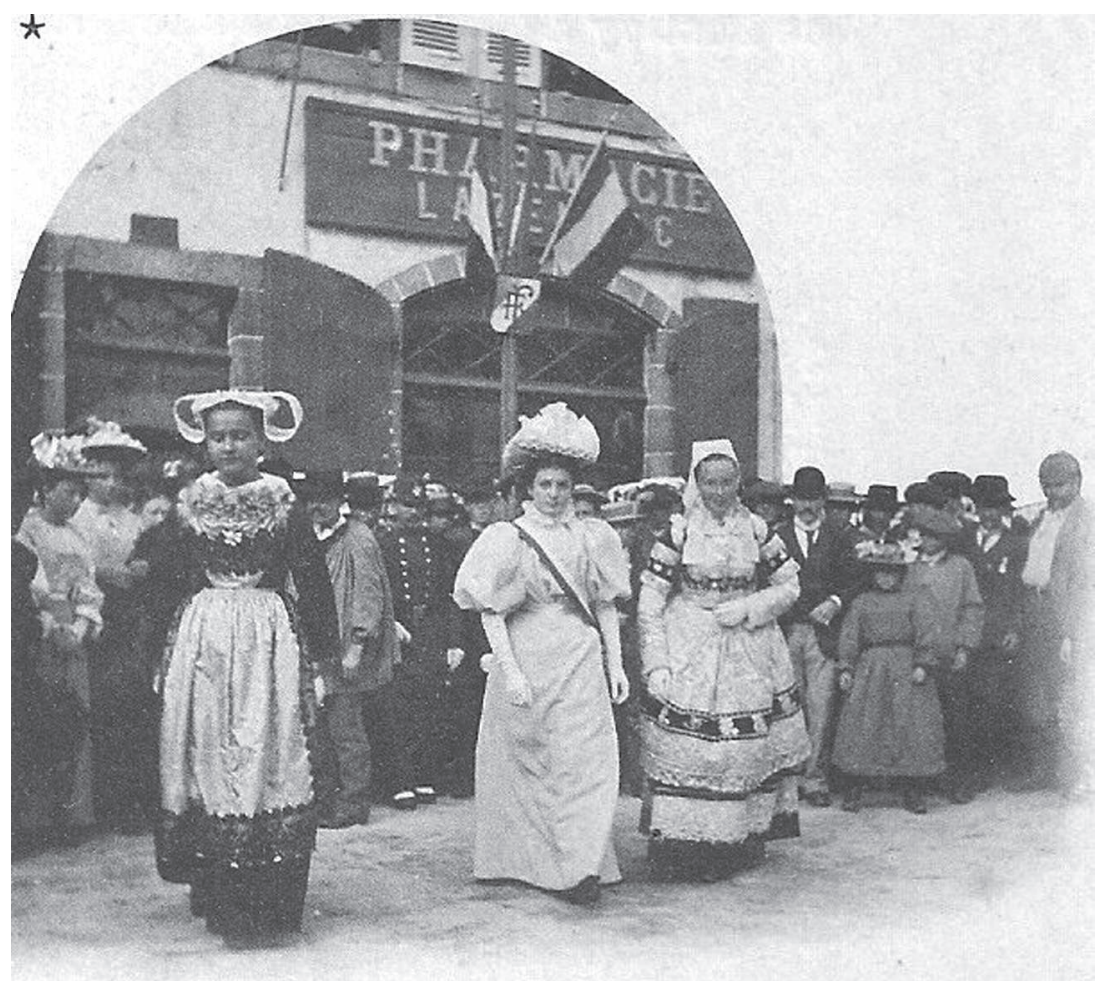

A Châteaulin.

\section{La nécessaire implication de la population}

À Pleyben, la population est mobilisée pour aménager l'espace communal et pour prêter, ou fournir, des éléments de décoration. Les sapins et la verdure des guirlandes sont offerts par les gens du bourg et des environs. Cette opération de transformation de l'espace commun mobilise aussi les habitants des communes voisines car cet arrêt présidentiel s'adresse à toute la population du canton. L'instituteur faisant partie de la commission d'organisation a œuvré auprès de ses collègues afin de mobiliser largement

18. Images extraites du livre officiel réalisé sur commande de l'Élysée : Les voyages du président de la République en Bretagne, août 1896, Paris, Berthaud-Frères, sd. Cet ouvrage acheté en souscription par les notables des communes visitées met en valeur le régime républicain et entend faire entrer la visite de Félix Faure dans l'histoire. Chaque grand voyage présidentiel dans les régions de France donne lieu à un album de ce type écrit par ces deux chroniqueurs attitrés. 
les scolaires : les enfants des écoles publiques du bourg, des hameaux, et des communes du canton, sont ainsi chargés de confectionner les guirlandes reliant les mâts les uns aux autres.

Pour la décoration intérieure de la mairie de Pleyben, il y a des travaux de peinture, de menuiserie, mais aussi beaucoup d'éléments apportés par les habitants du bourg : "Fauteuils, tapis, service de table, grands vases, tables, serviettes, nappes, [... ] fleurs de leurs jardins ${ }^{19}$. "Il y a aussi la réalisation, par les habitants, des rideaux en damas pour les fenêtres de la mairie et de tentures en calicot aux couleurs nationales afin de masquer la bibliothèque de la mairie. Aux murs, sont placés des écussons avec des petits drapeaux. Plus étonnant, les autorités font installer, dans la salle de réception, la photographie officielle du Président face un autre portrait de Félix Faure, en commandant des mobiles, installé sur le drapeau des mobiles de Pleyben. S'agit-il ainsi de relier le parcours personnel du visiteur (son action en 1870-1871 comme officier des mobiles) à la commune visitée dont plusieurs hommes composaient le $3^{\mathrm{e}}$ bataillon du Finistère qui défendit Paris et le gouvernement provisoire?

À Châteauneuf-du-Faou, sur $700 \mathrm{~m}$, le long du parcours que suivra le président, 800 drapeaux et 150 oriflammes seront mis sur des mâts et aux façades des maisons. Une partie de la décoration républicaine a été confiée à un " artiste peintre de Paris ${ }^{20}$ " installé dans la commune depuis 1894 . Ce peintre est Paul Sérusier, l'ami de Paul Gauguin, d'Émile Bernard et de Maurice Denis, qui a choisi de vivre dans ce bourg du Finistère intérieur après avoir séjourné à Pont-Aven et à Huelgoat. L'homme du Talisman (1888) apporte de manière régulière "son aide à la réalisation de bannières et de décors de théâtre ${ }^{21}$ "; c'est naturellement qu'il est sollicité pour prendre part à la décoration de la cité. Sérusier confirme dans une lettre à son ami Verkade qu'il a été chargé, avec Louis Vétel peintre vitrier et sacristain, de peindre 300 écussons aux armes de la France et de la Bretagne. Il supervise également la confection des guirlandes : cela lui donnera le sujet de son tableau intitulé "La guirlande de roses ${ }^{22}$ " (1898). Le clou de la décoration fut certainement l'arc de triomphe, très remarqué, réalisé selon les plans de Sérusier :

"Décoré de drapeaux et de rubans tricolores, de feuillages de toutes sortes, au milieu desquels étincelaient des faucilles, des faux et d'autres instruments agricoles, cet arc de triomphe était une merveille de grâce et de bon goût. Au-dessus de l'immense demi-cercle qu'il décrivait, on remarquait, avec un écusson aux armes de Bretagne, un beau dessin représentant l'agriculture et ses principaux produits, sous la forme symbolique de deux femmes, l'une les bras plein de gerbes de blé et l'autre tenant dans les mains des branches de pommier et une coupe remplie de cidre.

19. Arch. mun. de Pleyben, registre des délibérations du conseil municipal, 30 août 1896.

20. La Résistance, 22 août 1896.

21. Boyle-Turner, Carolyne, Sérusier et la Bretagne, Douarnenez, Le Chasse-marée/Ar Men, 1995, p. 97.

22. Huile sur toile, musée du Petit Palais, Genève. 
Au-dessous, en grosses lettres d'or, on lisait : Vive la République! Vive Félix Faure ${ }^{23}$ !"

S'ajoute à cette décoration agrico-républicaine, la présence de deux hommes en costume breton qui se placent de chaque côté de l'arc de triomphe " maniant comme à l'heure du travail, divers outils agricoles [devant le président] qui les remercie d'un paternel sourire ${ }^{24}$ ". Sérusier va ainsi chercher du côté de l'héritage des rites monarchiques pour le décor mais aussi pour en faire l'animation. Car on se trouve là, de manière assez exceptionnelle, devant une résurgence, certes épurée, des monuments éphémères de l'Ancien Régime devant lesquels se jouaient de courtes scènes de théâtre de rue, lors de la " passée du roi ", à l'occasion des entrées royales ${ }^{25}$. Ici, le thème économique, inscrit dans la République, l'emporte. L'agriculture fait vivre ces populations. C'est une réalité et plus encore une fierté qui est montrée ainsi au chef de l'État et à son président du conseil également ministre de l'agriculture. Tout cela entre dans le contexte politique marqué par le " ruralisme " de certains républicains qui, comme Jules Méline, estiment qu'il est important, face à la montée jugée menaçante du mouvement ouvrier dans les villes, que la République soit équilibrée par les campagnes.

La mise en place étant achevée la veille de l'arrivée de Félix Faure, la municipalité donne la possibilité à tous de découvrir les aménagements réalisés : cela fait l'admiration des habitants du bourg et de la campagne qui étaient admis à visiter les deux salles. Cette ouverture au public d'un lieu qui sera ensuite un espace réservé aux officiants est une manière de reconnaître la qualité du travail fourni et dont chacun peut être fier. Cela n'est pas sans rappeler que lors de la visite de l'empereur en 1858, les appartements occupés par le couple impérial, à la préfecture de Quimper, furent ouverts au public après leur départ. Pénétrer dans les lieux est donc une forme de participation du peuple : sous le Second Empire c'était une fois le couple parti; en République, c'est en avant-première!

\section{Le spectacle présidentiel au village}

\section{Une fête digne du " 14 juillet »}

Cette implication populaire montre l'adhésion à ce qui s'annonce être une fête républicaine ${ }^{26}$ au village. En effet, à côté des cérémonies protocolaires, cette journée doit être pour le peuple celle des réjouissances et des distractions. À Carhaix, la matinée est réservée aux réceptions officielles tandis que l'après-midi sera le moment de la fête. Afin de marquer le départ de Félix Faure, le maire appelle ses concitoyens à former un cortège à cheval et en costume breton pour accompagner le président à sa sortie de Carhaix.

23. La Dépêche de Brest, 13 août 1896.

24. Ibidem.

25. Burguière, André et Revel, Jacques (dir.), Histoire de France. La longue durée de l'État, Paris, Le Seuil, coll. « Point-Histoire ", 2000, p. 241.

26. IHL, Olivier, La Fête républicaine, Paris, Gallimard, 1996. 
À Châteauneuf-du-Faou, la population est conviée à participer aux festivités, avant et après le départ du cortège officiel, selon le programme suivant :

" $11 \mathrm{~h}$ courses de chevaux/13 h course de femmes avec cruche/14 h 30 réception du président de la République/15 h course en $\mathrm{sac} / 16 \mathrm{~h}$ course de retour pour les chevaux ayant escorté Félix Faure/17 h pots surprises/18 h 30 course d'hommes/Toute la journée : danses au biniou/Le soir : danses sous les halles décorées et illuminées/ $22 \mathrm{~h}$ retraite aux flambeaux et illumination générale de la ville."

À Pleyben, la fête débute avant l'arrivée de Félix Faure. Pour distraire la population, il y a une course de vélocipèdes, une course de chevaux entre les cavaliers venus à la rencontre du Président, des danses en plein air et des joueurs de binious. Le temps de la visite officielle fut ici le temps de la suspension de la fête qui put continuer dans l'après-midi et la soirée. Le maire avait d'ailleurs pris un arrêté autorisant tous les cafés, cabarets et débits de boisson existant au chef-lieu de la commune de Pleyben à rester exceptionnellement ouverts jusqu'à minuit. S'il s'agit là de lieux de distraction, le cabaret, venu de la ville, est devenu au cours du XIX ${ }^{\mathrm{e}}$ siècle, à la campagne, un espace important de la sociabilité villageoise où l'on parle politique ${ }^{27}$.

Chacun doit pouvoir participer à l'événement. Et si l'Église a ses pauvres, la République a ses indigents, à qui la municipalité remet du pain. À Carhaix, la distribution de pain a lieu la veille de la visite présidentielle; à Châteaulin, c'est le matin. À cette action en faveur des pauvres, il faut ajouter le don fait par le président lors de son passage : $100 \mathrm{~F}$ sont distribués le 17 août par le bureau de bienfaisance de Pleyben en octroyant $1 \mathrm{~F}$ par famille inscrite au tableau communal.

Avec la visite présidentielle au village, les populations rurales connaissent une rupture dans leur quotidien. Leur cadre de vie habituel est « républicanisé " et même embelli. L'événement attendu, préparé, et auquel chacun a la liberté d'assister, est une occasion rare pour ces populations de participer à une cérémonie officielle. Il y a aussi la fête républicaine avec sa décoration, son programme de réjouissances et l'irruption de la musique, des jeux, du sport, des rencontres, peut-être même d'une certaine fraternisation sociale dans ce contexte politique et festif élargi aux communes environnantes. C'est ce qui apparaît lorsque la municipalité de Pleyben dresse le bilan de cette journée : elle se félicite de constater que "la plus parfaite entente n'a cessé de régner entre tous les habitants du bourg et ceux des communes voisines ${ }^{28}$ ". La visite du Président au village a donc pour vertu de fédérer, le temps de cette journée historique.

27. VIGREuX, Jean, "Les campagnes françaises et la politique (1830-1914)", Parlement[s] $\mathrm{n}^{\circ} 5,2006$, p. 62.

28. Arch. mun. de Pleyben, délibération du conseil municipal, 30 août 1896. 


\section{L’accueil du président de la République}

Figure 2 - Devant l'église de Châteauneuf-du-Faou, la foule vient de voir passer le cortège présidentiel dans une ambiance républicaine tintée de tricolore

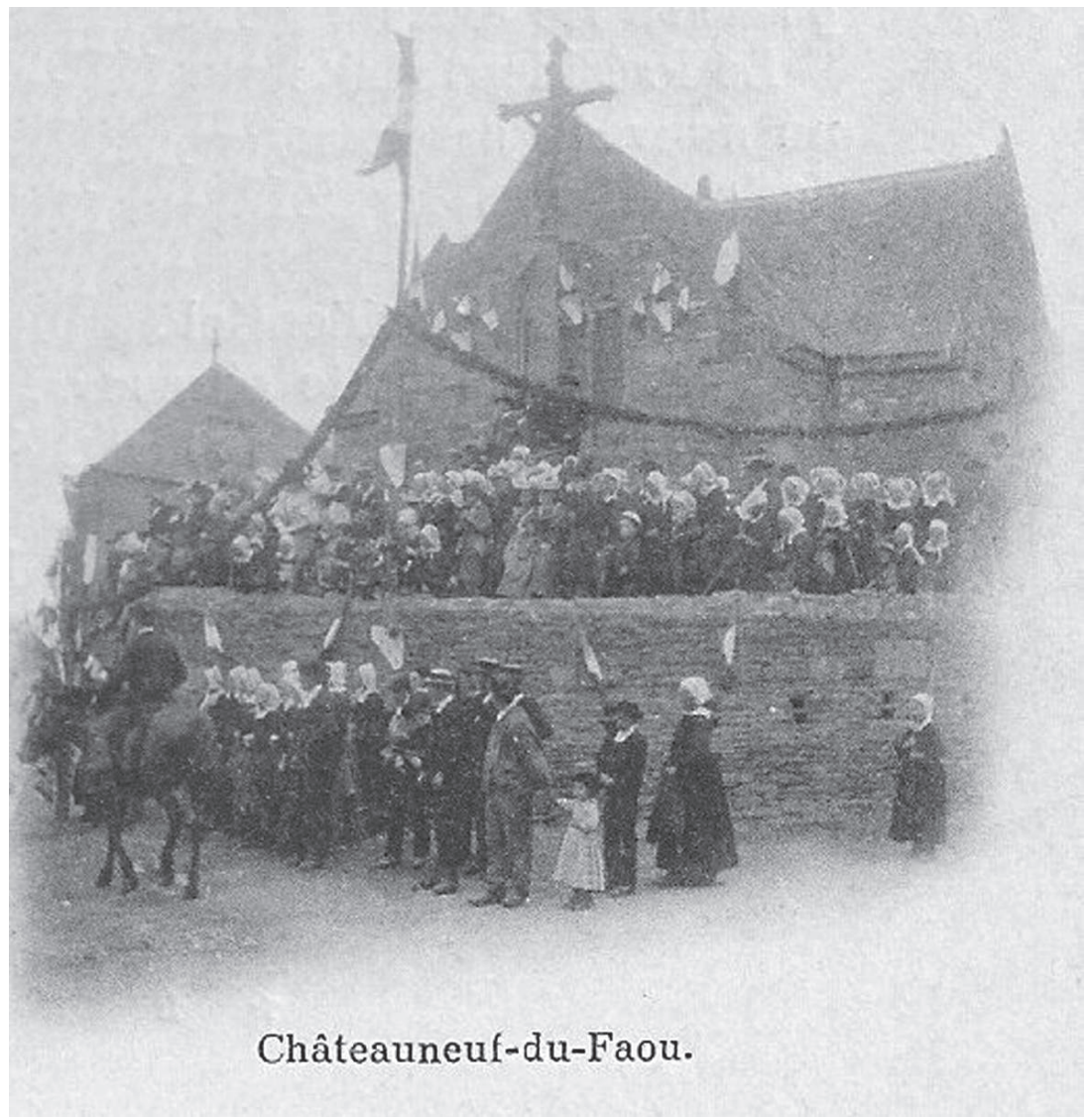

Ce qui frappe tout d'abord, c'est le respect scrupuleux des rituels républicains dans ces petites communes. L'ensemble des marqueurs républicains qui concourent à la mobilisation est utilisé. À Châteauneuf-du-Faou, le cortège présidentiel est accueilli bien avant l'entrée dans le bourg par des mâts portant des drapeaux et reliés entre eux par des guirlandes de verdure formant une avenue sur le trajet du cortège. Le passage sous un arc de triomphe marque de manière symbolique son entrée dans l'espace communal puis c'est l'arrivée jusqu'à l'épicentre des cérémonies au son des " cloches nationales" (Alain Corbin) comme à Pleyben. Le maire se 
trouve là au cœur de la cérémonie d'accueil; il reçoit le chef de l'État et présente les membres de son conseil municipal. Il y a ensuite l'échange des discours et des cadeaux. Un bouquet de fleurs est offert au Président, comme à Pleyben, où il est présenté noué d'une écharpe en soie tricolore et remis par le fils du maire de Lothey et par la fille du $2^{\mathrm{e}}$ adjoint au maire de Pleyben. Lors de la réception en mairie, Félix Faure reçoit des mains de l'ancien député Le Breton une photographie du calvaire et de l'église. Dans les grandes villes, le chef de l'État est systématiquement reçu à l'hôtel de ville, à la préfecture ou à son arrivée à la gare. Lors de son parcours dans le Finistère intérieur, les lieux dédiés à l'accueil présidentiel sont : la gare (trois fois), le marché couvert (deux fois), l'école publique (une fois) et la mairie (une fois). Est-ce à dire que les lieux typiquement républicains sont encore rares dans cette partie de la Bretagne?

$\mathrm{Si}$, entre Morlaix et Carhaix, les deux haltes se limitent à l'espace de la gare, c'est pour des raisons d'efficacité. À l'arrêt (non prévu initialement) de Scrignac-Berrien, le maire de Scrignac présente les conseillers municipaux et échange quelques paroles avec Félix Faure. À celui de LocmariaHuelgoat, l'accueil " est chaleureux, digne de ce chef-lieu de canton qui a toujours compté parmi les plus républicains du département ${ }^{29}$ ". À Carhaix, on accueille aussi le président à la gare, où les salles d'attente ont été transformées en salons de réception : le maire et ses conseillers municipaux, les maires et les fonctionnaires du canton, le conseiller général, les instituteurs et des membres du clergé y sont tous réunis. "À chaque groupe, [le président] adresse des paroles aimables ${ }^{30}$ ". La Marseillaise est jouée et Félix Faure remet deux médailles. L'escorte qui encadre le cortège présidentiel est constituée d'un escadron du $2^{\mathrm{e}}$ chasseur à cheval de Pontivy et contribue à la solennité de la visite.

Le marché couvert est l'endroit réservé au déjeuner à Carhaix. Certains font connaître, dans la presse, leur préférence pour qu'il se tienne sous une tente, sur la place, devant la statue de La Tour-d'Auvergne. À Châteaulin, la cérémonie d'accueil doit se faire sous les halles couvertes. À l'intérieur, les piliers, avec trophées, sont reliés par des guirlandes de mousse et de houx et le pavé est recouvert de tapis, tandis que, sur les murs, des étoffes sont tendues et des rideaux de couleur installés sur les portes. À l'extérieur, de nombreux drapeaux et trophées pavoisent le bâtiment. C'est là que le vin d'honneur est servi : une large draperie tricolore a été installée derrière la table d'honneur où chacun aperçoit le buste de la République sur un piédestal assez élevé. Pour pénétrer dans l'espace communal, dont la voirie a été recouverte de sable afin de cacher son mauvais état, le cortège présidentiel est passé, route de Pleyben, sous un arc de triomphe associant verdure et mâts tricolores, puis sous celui réalisé par la gendarmerie locale et enfin, à l'entrée de la place, sous un troisième où figure la dédicace : "À Félix Faure, la ville de Châteaulin ". À Châteauneuf-du-Faou, il est reçu

29. Le Finistère, 11 août 1896.

30. La Résistance, 22 août 1896. 
Figure 3 - Félix Faure est reçu à la gare de Carhaix dont les salles d'attente sont aménagées en salons de réception

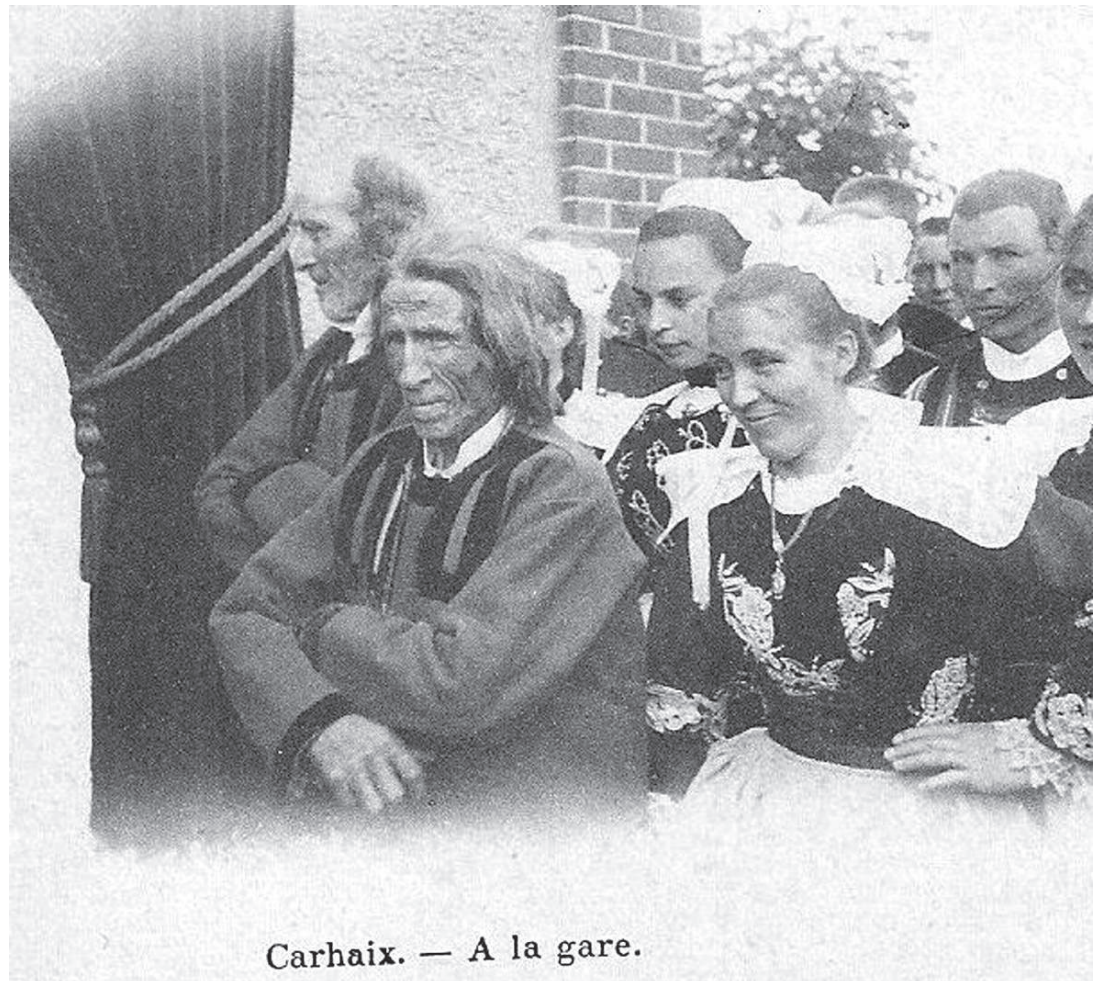

dans l'école publique des garçons. Lors de ce voyage en centre Finistère, le président de la République n'est reçu que dans une mairie, celle de Pleyben, à un moment où ce bâtiment symbolise l'esprit républicain. Sans doute peut-on trouver là un témoignage de la difficulté des municipalités rurales à se doter, pour des raisons économiques, en cette fin du XIX ${ }^{\mathrm{e}}$ siècle, de "maison commune".

\section{Les républicains « historiques » au rendez-vous}

Se rendre dans une commune, c'est marquer la reconnaissance de la République pour l'action présente mais c'est aussi l'occasion de mettre en lumière des itinéraires modèles. Le récit de la rencontre entre Félix Faure et Joseph Nédellec est repris dans toute la presse. Dans le journal républicain, Le Finistère, on lit sobrement : "Nous distinguons dans l'assistance, près de M. Méline, M. Nédellec, ancien député républicain de Carhaix, l'un des 363. À La gare, le Président avait eu avec lui un entretien particulier 
et lui avait témoigné de toutes ses sympathies ${ }^{31}$. " Cet extrait met en évidence autant la sobriété que la réalité de la relation privilégiée entretenue avec le chef de l'État. La conservatrice Résistance relate aussi la présentation de Joseph Nédellec à Félix Faure; mais elle en profite pour glisser un petit coup de griffe : "L'un des 363 de Gambetta, toujours ferme républicain mais aujourd'hui heureusement revenu, croyons-nous, des opinions

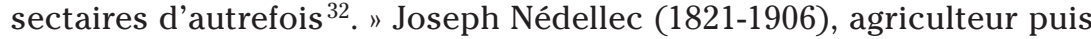
notaire, fut maire de Carhaix et député de la deuxième circonscription de Châteaulin de 1876 à 1881 ; ce républicain " très modéré et catholique ${ }^{33}$ " qui siège alors au centre-gauche fit partie des 363 députés ${ }^{34}$ qui signèrent, en mai 1877 , le manifeste dénonçant la politique conservatrice du président du Conseil, Broglie. Ces députés républicains s'engagèrent, sous l'autorité de Gambetta, dans une lutte ouverte contre cette "politique de réaction et d'aventures ${ }^{35}$ ", et votèrent un ordre du jour de défiance à l'encontre du gouvernement de Broglie le 18 juin 1877. C'est bien un républicain " historique " qui est présenté au président; d'autant plus que son parcours personnel illustre la méritocratie républicaine : issu d'un milieu modeste, enraciné à Carhaix, dont il devint le représentant à Paris, il fut un homme opposé au cléricalisme et aux aristocrates. Adversaire d'une république présidentielle, il fut partisan d'une république parlementaire. Réélu en 1877, il apporta son concours à la politique opportuniste avant de se retirer en 1881.

Puis, c'est à Pleyben que Félix Faure côtoie une autre figure républicaine. En effet, Louis Le Breton, 89 ans, était l'un des six républicains du Finistère élus en 1848 à l'Assemblée nationale constituante. Là encore, l'itinéraire personnel et l'engagement politique pouvaient servir le " modèle républicain ". Fils du percepteur de Pleyben, chirurgien de marine sous la Restauration, il participe à la prise d'Alger en 1830. Reçu docteur en médecine à Paris en 1834, il s'installe dans sa commune natale. Devenu le correspondant pour la région du journal républicain Le National, il reçoit les souscriptions pour les délits de presse et pour les détenus politiques. Député républicain, il siège au centre gauche et soutient Cavaignac; il vote avec le parti du National : pour le bannissement de la famille d'Orléans, pour les poursuites contre Blanc et Caussidière, et pour l'abolition de la peine de mort mais contre l'impôt progressif. Il montre ensuite une " hostilité clairvoyante à la politique du prince-président ${ }^{36}$ ", se révèle un adversaire modéré mais très ferme de la politique de l’Élysée. Battu aux

31. Le Finistère, 11 août 1896.

32. La Résistance, 22 août 1896.

33. PAUBERT, Laurent, "Électorat du centre et modération politique en Bretagne sous la $3^{\text {e }}$ République : l'exemple du Finistère et du Morbihan ", Annales de Bretagne et des Pays de l'Ouest, tome 111, n 1, 2004, p. 70.

34. DuCleRT, Vincent, La République imaginée (1870-1914), Paris, Belin, 2010, p. 142.

35. Mayeur, Jean-Marie, Les débuts de la Troisième République (1871-1898), Paris, Le Seuil, " Points-histoire ", 1973, p. 39.

36. L'Avenir de Morlaix, notice nécrologique, 24 octobre 1896. 
législatives de mai 1849, il est victime de la politique répressive après le coup d'État du 2 décembre 1851 : «M. Le Breton eut l'honneur d'être l'un des premiers désignés pour la proscription ${ }^{37}$. "Réélu député en juillet 1871, puis conseiller général en octobre, il se retire de toute activité politique active après 1885. Par le mariage de sa fille avec Félix Hémon, Louis Le Breton était lié à cette grande famille républicaine qui dirigeait le journal Le Finistère ${ }^{38}$.

Louis Le Breton remet donc le cadeau de la municipalité au président de la République. Au-delà, c'est bien entendu l'occasion de rappeler l'itinéraire exemplaire du "doyen des républicains du département " ainsi que le désigne le maire dans sa présentation à Félix Faure. Chacun souligne le désintéressement de cet homme dont « les services politiques et ses bienfaits médicaux lui [valent] une légitime popularité ${ }^{39}$ " auprès de la population. Le Finistère se plaît à rappeler qu'il y a quelques années " la Croix de la légion d'honneur avait été offerte à M. Le Breton. Il l'a refusée; mais il porte la médaille coloniale qui lui a été décernée en commémoration de sa présence à la prise d'Alger en $1830^{40}$ "; Louis Le Breton ne s'est pas expliqué sur la signification qu'il donnait à ce choix. On peut formuler l'hypothèse que cela ne doive rien au hasard de se montrer ainsi décoré au moment même où Félix Faure venait de signer, la veille à Brest, la promulgation de la loi déclarant Madagascar et les îles voisines, colonies françaises. L'ancien député de 1848 se retrouvait-il dans la défense de la mission civilisatrice de la France au nom du " devoir de civilisation qu'impose aux sociétés européennes leur supériorité présente face à certaines sociétés non occidentales ${ }^{41}$ ", comme de nombreux républicains alors?

En tous les cas, cette personnalité mise en valeur à Pleyben apparaît être une sorte d'incarnation de l'action engagée au long du XIX siècle par ces Bretons en faveur de la République : «Le Président remercie avec effusion M Le Breton et déclare qu'il est heureux de rendre hommage en sa personne au vieux parti républicain du Finistère. Ce parti ne peut être mieux personnifié, en effet, que par M. Le Breton, dont la carrière politique est toute d'honneur, de désintéressement et de loyauté ${ }^{42}$. " L'émotion présidentielle évoquée par le journaliste vient en appui des valeurs républicaines mises en lumière à travers la biographie de Louis Le Breton : fidélité au régime républicain, engagement et désintéressement, dévouement pour ses concitoyens comme médecin. Le rappel de son refus d'accepter la Croix de la légion d'honneur place-t-il cet ancien quarante-huitard (Maurice

37. Ibidem.

38. Il est donc le grand-père de Louis Hémon (1880-1913), l'auteur de Maria Chapdelaine. Sa fille Louise s'était mariée à Félix Hémon qui fut en 1889, chef de cabinet d'Armand Fallières, ministre de l'Instruction publique.

39. Le Finistère, 11 août 1896.

40. Ibidem.

41. GIRARDET, Raoul, L'Idée coloniale en France de 1871 à 1962, Paris, Hachette littératures, 1972, p. 163.

42. Le Finistère, 11 août 1896. 
Agulhon) dans la ligne de ces républicains qui refusèrent la « médaillocratie " par " refus du bûcher des vanités ${ }^{43}$ "?

\section{Peu de remises de médailles dans le centre Finistère}

La remise de médailles est un des moments forts du cérémonial républicain. À côté de la promotion du 14 juillet, la visite présidentielle est une nouvelle occasion de remettre des décorations. Lors de ce voyage, Félix Faure remet dans le Finistère au moins 126 médailles ${ }^{44}$, surtout à Brest et à Quimper. En ce qui concerne la visite de l'intérieur du département, il n'y a que 12 décorations remises, soit 9,5\% du total. Sont décorés : six ouvriers, deux militaires, un fonctionnaire, un élu, un agriculteur, une religieuse. La médaille la plus prestigieuse est la Croix de chevalier de la légion d'honneur remise à Morlaix à un capitaine du $118^{\mathrm{e}}$ de ligne. Les autres décorations attribuées sont les Palmes académiques, le Mérite agricole, des médailles d'honneur du travail, des médailles d'argent pour actes de dévouements.

L'étonnement réside surtout dans le peu de remises du Mérite agricole, médaille créée par Jules Méline, présent aux côtés de Félix Faure dans cette partie du Finistère où dominent la ruralité et l'agriculture. Ceci étonne d'autant plus que le contexte politique pouvait le justifier. Président du Conseil depuis avril 1896, Méline est au plan économique un défenseur du protectionnisme agricole et s'engage, avec l'accord de Félix Faure, dans une politique d'apaisement des querelles religieuses. Cette séquence du voyage en Bretagne, pouvait permettre de courtiser ce monde agricole en distinguant plus de cultivateurs exemplaires. À moins que sa présence et les marques de sympathie qu'il suscite ne se suffisent à elles mêmes? Au total, les personnes décorées sont, pour l'essentiel, issues de milieux modestes; manière de montrer l'intérêt porté par la République au peuple de l'usine et des campagnes.

\section{Le Président sur la terre d'un héros national}

Carhaix s'est parée de ses habits républicains et le cortège officiel passe devant les maisons pavoisées et décorées de fleurs, de verdure et sous deux arcs de triomphe, l'un placé au milieu de la Grande rue, l'autre étant à l'entrée de la place du Champ-de-Bataille où doit se dérouler l'hommage à La Tour d'Auvergne. C'est immergé dans ce décor républicain, que Félix Faure salue le grand homme, entouré des généraux, des officiers de son cabinet, des élus du département et du canton. L'instant est solennel : chacun se découvre pour entendre Le Chant du départ et La Marseillaise, " cet hymne qui a guidé les armées de la première République à la conquête du

43. InL, Olivier, Le Mérite et la République. Essai sur la distinction des émules, Paris, Gallimard, 2007, p. 269.

44. Les archives départementales du Finistère n'en conservent pas de traces. On arrive à ce chiffre en recoupant les informations, incomplètes, parues dans la presse et celles publiées dans l'album de Paul Gers et de Paul Belon. 
Rhin ou des Pyrénées, avec La Tour d'Auvergne au premier rang ${ }^{45}$ ". À ce moment là, rapporte le journaliste du Finistère, " tous les cœurs se dilatent; l'émotion est indicible. Du haut de son piédestal, le héros reçoit cet hommage et son geste semble y répondre ${ }^{46}$ ". L'arrêt présidentiel, devant la statue de cet enfant que Carhaix a donné au pays, est à intégrer dans la volonté de la Troisième République de faire de la pédagogie républicaine par l'exemple. C'est même pour tous une évidence : "Comment un chef d'État républicain eût-il pu traverser Carhaix sans aller s'incliner devant la statue de La Tour d'Auvergne ${ }^{47}$ ? " Cette statue ne doit pas sa réalisation à la " statuomanie » républicaine. Érigée en 1841, elle est fille de cette monarchie de Juillet qui initia " la première grande invasion de la statuaire publique ${ }^{48}$ ". Elle est un hommage pédagogique et porte quatre hauts-reliefs illustrant des moments forts : il y a son acte de bravoure en 1781-1782, la prise de Fort-Barreau en septembre 1792 qui entraîne un nouveau rattachement de la Savoie à la France, son départ pour remplacer à l'armée le fils d'un ami, sa mort héroïque en 1800 en Allemagne. Ces quatre épisodes définissent le héros et fixent la mémoire de cet homme salué dans le panthéon local carhaisien.

Félix Faure reçu au village :

\section{l'identité bretonne, le verbe et l'acclamation}

\section{Les Bretons en costumes : \\ l'expression de la bretonnité et de la ruralité}

L'expression de l'identité bretonne est présente durant cette journée passée loin des centres urbains de Brest et de Quimper. La presse cherche à relever des marqueurs identitaires dans la confection des menus proposés lors du déjeuner et des trois vins d'honneur. Le programme dans le centre Bretagne faisait de Carhaix la commune destinée à accueillir le repas de la mi-journée. Dès les préparatifs ${ }^{49}$, l'Élysée avait prévu que ce déjeuner serait offert par le Président, à sa suite et à ses invités ${ }^{50}$ (entre 50 et 60 personnes) et qu'il durerait de 10 heures 30 à 11 heures 30. Le marché couvert est alors le seul endroit permettant d'accueillir dans de bonnes conditions les convives. Ceci est assez classique dans les petites communes, comme le précise Olivier Ihl ${ }^{51}$, lorsque les invités sont nombreux et que la mairie ne possède par de salle de réception ni de salles de classe adaptées. Les invi-

45. Le Finistère, 11 août 1896.

46. Ibidem.

47. Ibid.

48. Agulhon, Maurice, "La statuomanie et l'histoire " dans Histoire vagabonde, tome 1, Paris, Gallimard, 1988, p. 163.

49. Arch. dép. du Finistère, 1 M 317, lettre du commandant Moreau, attaché à la maison militaire du Président, au Préfet, 14 juillet 1896.

50. Arch. mun. de Carhaix, délibération du conseil municipal, 10 juillet 1896.

51. IHL, Olivier, "Convivialité et citoyenneté. Les banquets commémoratifs dans les campagnes républicaines à la fin du XIX ${ }^{\mathrm{e}}$ siècle ", dans CoRBIN, Alain, GÉRÔME, Noëlle, 
tés sont le maire et les conseillers municipaux de Carhaix, les maires et les principaux fonctionnaires des neuf communes du canton, et les personnes qui composent le cortège présidentiel. Cette liste semble évidente compte tenu de cette volonté affichée d'honorer la république des cantons. Or, un télégramme officiel du 6 août révèle qu'il y a eu, en sous-main, un rapport de force tendu à propos du déjeuner présidentiel; tension dont la presse n'a pas eu connaissance : tous les maires du canton de Carhaix ont fait clairement savoir au sous-préfet de Châteaulin leur refus "d'aller rencontrer le Président car [ils ne sont] pas invités à déjeuner ${ }^{52}$ ". À quelques heures de la venue de Félix Faure, cette menace porte : l'absence ostentatoire des élus serait venue, à coup sûr, ternir la visite et rompre avec l'idée essentielle de communion républicaine. Il n'y a pas d'autres traces conservées aux archives de cet épisode mais le résultat est là : le 8 août les neuf maires du canton de Carhaix figurent sur la liste des invités pour le déjeuner.

Le sens donné au menu n'est pas le même chez les républicains et chez les conservateurs. Le repas proposé est composé de langoustes, d'omelette au lard, d'andouilles à la purée, avec comme boisson du cidre. Pour la presse républicaine, le Président offre ici le " premier menu vraiment local que nous ayons rencontré sur notre route [...] de quoi mettre en joie des estomacs bretons ${ }^{53}$ ". L'aspect régional de ce repas réside peut-être dans l'association de la langouste (produit de luxe issu de l'armor) aux aliments plus rustiques et banals du monde rural (œufs, lards, andouille issus de l'argoat), tout cela complété par du cidre, boisson encore majoritairement consommée. De son côté, la presse conservatrice n'y voit rien d'autre qu'un «bon déjeuner bourgeois aussi bien normand que breton [...] [alors que] l'on avait parlé de mets nationaux c'est-à-dire bretons ${ }^{54}$ ".

L'aménagement et la décoration de la salle restent à la charge de la mairie qui a mobilisé les bonnes volontés afin d'embellir l'espace de réception : les draperies rouges se rejoignent de façon à masquer complètement la nudité des murs en entourant de grandes glaces empruntées aux armoires carhaisiennes; nouvelle preuve de l'intelligence bretonne selon le journaliste du Figaro : "Les Bretons sont décidément ingénieux. Savez-vous avec quoi ils ont décoré le marché? Avec des portes d'armoires à glaces appliquées sur de l'andrinople ${ }^{55}$ ! „En revanche, il n'est pas fait mention de marqueurs républicains ayant pu solenniser l'endroit : ni buste de Marianne, ni photographie de Félix Faure, ni drapeaux tricolores ne sont évoqués par la presse, qu'elle soit locale ou nationale. Lorsque le président offre le repas, la règle veut, comme ici, qu'on ne porte pas de toasts. Il n'y eut pas non plus d'échanges de discours à ce moment là.

TARTAKOWsky Danielle (dir.), Les Usages politiques des fêtes aux XIXe-XXe siècles, Paris, Publications de la Sorbonne, 1994, p. 143.

52. Arch. dép. du Finistère, 1 M 317, télégramme du sous-préfet de Châteaulin au préfet, 6 août 1896.

53. Le Finistère, 11 août 1896.

54. La Résistance, 22 août 1896.

55. Le Figaro, 9 août 1896. 
La touche locale est donnée tout au long de cette journée, ce qui n'est pas sans satisfaire la presse parisienne qui aime donner dans le pittoresque. Partout, la musique est présente et joue des notes bretonnes. À Scrignac, " c'est l'aubade des binious ${ }^{56}$ ". À Carhaix, la société musicale, qui a joué durant le repas les morceaux de son répertoire, dont le vieil air An hini gozh, veut reprendre La Marseillaise au moment où Félix Faure se lève pour quitter la salle mais le président intervient et redemande An hini gozh. À Châteauneuf-du-Faou, les binious jouent l'hymne national, proposant de la sorte une incarnation sonore de l'union de la petite et de la grande patrie.

\section{Figure 4-L'accueil présidentiel au village se fait au son de binious et de cornemuses qui interprètent l'hymne national}

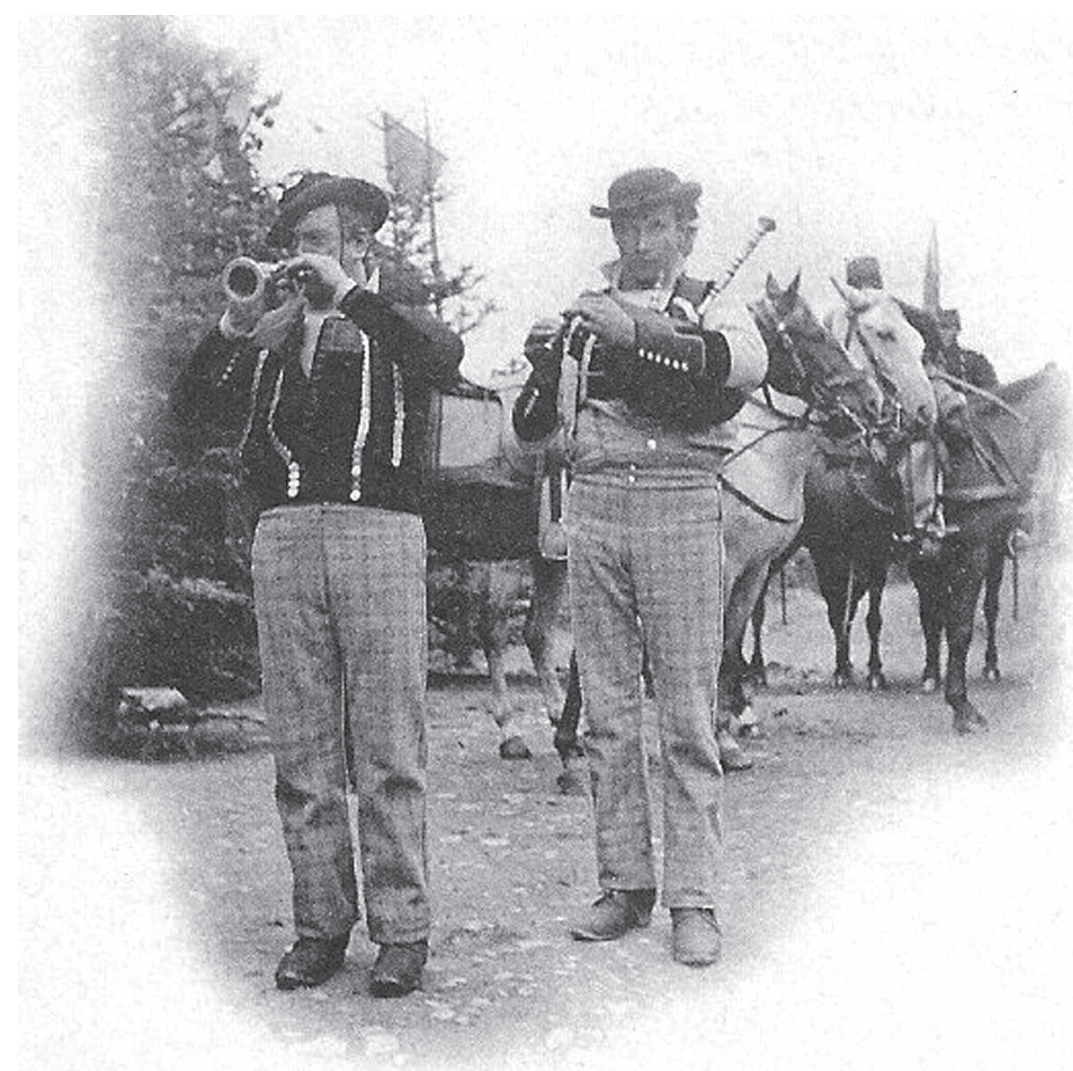

De Carhaix à Châteaulin.

56. Ibidem. 
Une des expressions les plus visibles de la bretonnité est celle des différents costumes " nationaux " que le cortège présidentiel découvre durant le voyage. Les autorités avaient clairement demandé à la population de venir participer en tenue de fête. Du coup, pour les membres de la délégation officielle, et pour la presse, il s'agit d'une réelle plongée au cœur des traditions bretonnes. À Carhaix par exemple, l'envoyé spécial du Siècle note que la réception " prend un caractère qu'elle n'a pas encore eu depuis notre arrivée en Bretagne. Les conseils municipaux de Plouguer, Carhaix, des différentes communes du canton sont là, en veste bretonne brodée de rouge, de jaune et de bleu. [...] On longe de nouveaux groupes de paysans et de paysannes toujours en costume pittoresque ${ }^{57}$ ". Ainsi, la multitude des costumes apparaît à tous, portés par des élus locaux et par le peuple paysan. Certains journalistes, qui trouvent ceux de Carhaix "sévères ", s'enthousiasment en revanche pour ceux " éclatants " de Scaër ou ceux " gracieux " de Châteaulin.

C'est d'ailleurs à Châteaulin que les journalistes qui accompagnent le président ont acheté, en guise de souvenir local, des chapeaux bretons. "Le président, à ce moment-là très gai, nous a invités à les mettre, et depuis le matin nous rendons, sous le chapeau noir aux longs rubans de velours, hommage à la Bretagne ${ }^{58}$. " Porter le chapeau pour faire couleur locale au risque d'être ridicule n'est pas envisageable, alors il convient de prévenir : "Il ne faut pas rire, ce chapeau irait très bien à tout le monde, seulement il est d'un lourd ${ }^{59}$ ! "S'il ne permet pas l'élégance, est-ce parce qu'il reste un élément de la tenue paysanne, donc considéré comme fruste? Car la réalité s'impose : les costumes bretons sont alors un des signes forts de l'appartenance à une communauté paysanne traditionnelle. Il n'en reste pas moins vrai que c'est une étonnante manière de souligner que l'hommage rendu peut aussi prêter à rire.

Si les différents marqueurs de l'expression de la bretonnité semblent acceptés durant la visite présidentielle (danses et musique bretonnes, costumes traditionnels, aliments typiques), l'élément central de cette identité est le grand absent. En effet, la question de l'expression, de la pratique, ou même de l'existence d'une langue encore parlée au quotidien par l'écrasante majorité de la population, n'est jamais abordée. La presse, nationale ou locale, ne pose pas le problème de la compréhension des discours échangés en français entre les notables locaux et Félix Faure. Est-ce à dire que l'on part du principe que cette phase de la visite ne s'adresse pas directement au peuple? Ces échanges de discours se déroulent en effet dans des espaces fermés où se concentrent les officiants francophones. Comment dès lors ce cérémonial officiel est-il perçu par ce peuple venu en foule et qui ne comprend pas le français? C'est une question que personne ne pose. Une allusion a pu être relevée lorsque Le Figaro relate l'arrivée de Félix Faure à Carhaix : le président

57. Le Siècle, 9 août 1896.

58. Le Figaro, 10 août 1896.

59. Ibidem. 


\section{Figure 5 - Les costumes traditionnels font l'objet de l'attention de la presse nationale qui souligne leur pittoresque tout au long du voyage}

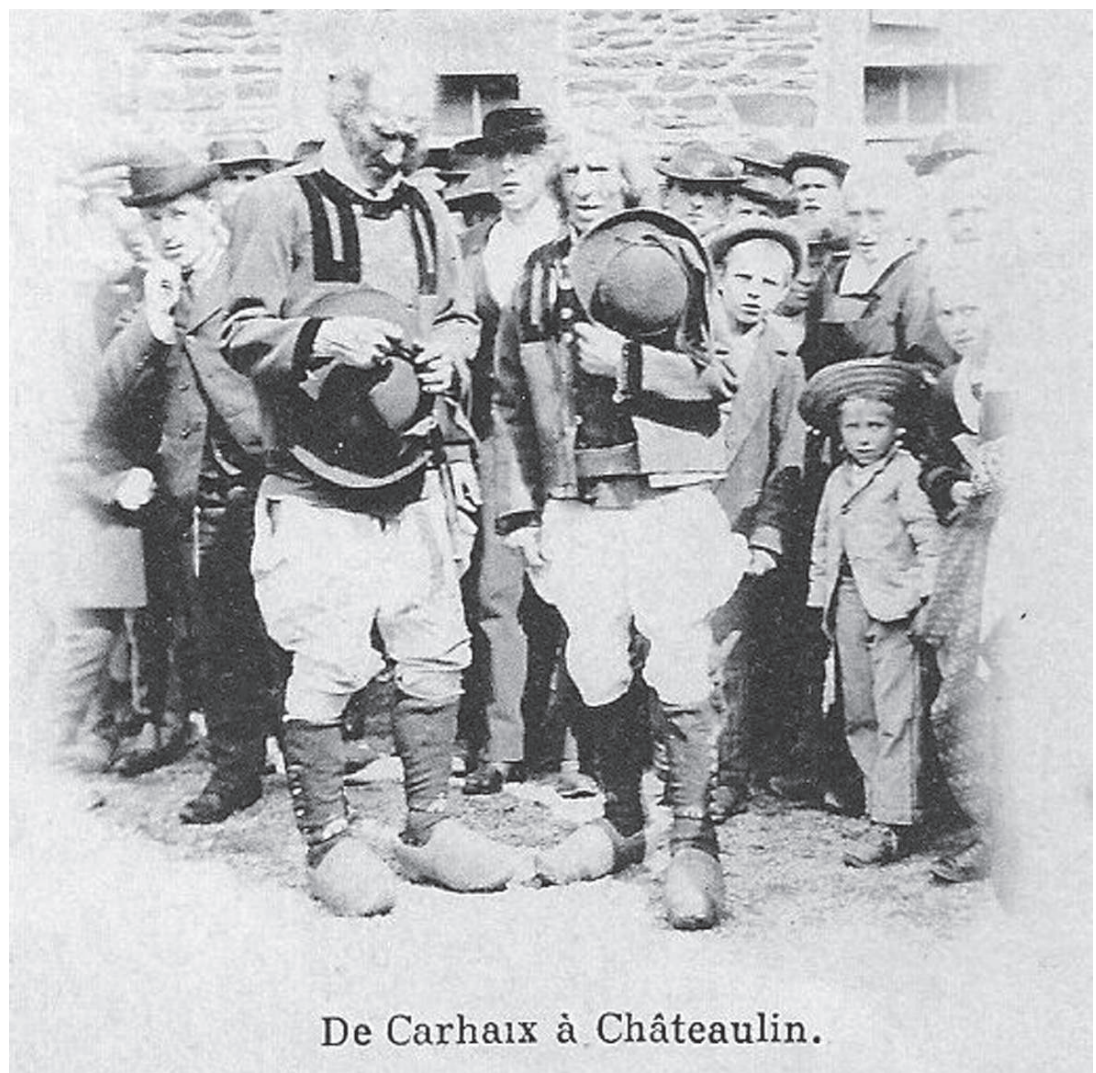

interroge les personnes qu'il rencontre à la gare et il est surpris de ne pas recevoir de réponse : «À partir de cette commune, cela lui arrivera souvent : il parait que $70 \%$ des habitants ne comprennent pas le français. Qu'ont fait depuis 25 ans les ministres de l'Instruction publique? „ Est-ce justement pour associer ses concitoyens que le député-maire Le Borgne achève son allocution ainsi : " En terminant, je vais remplir le vœu des habitants du canton de Pleyben en les invitant à crier avec moi dans ma langue maternelle, dans notre vieille langue bretonne: Buhez vad da Félix Faure! Hag lavaromp a darre voez huel, lavaromp et galleg : Vive le président de la République! Vive les ministres! Vive la République ${ }^{60}$ !

60. Arch. mun. de Pleyben, discours du maire devant Félix Faure, 30 août 1896. Traduction : "Bonne vie à Félix Faure! Et nous disons à nouveau à voix haute et en français..." 


\section{L'usage de la parole devant le président de la République}

Dans cette visite du Finistère intérieur, les lieux où l'on parle au chef de l'État sont les gares, l'école publique, la mairie. S'adresser au président est un privilège réservé à quelques personnes. Rien n'est spontané et c'est une parole sous contrôle qui s'exprime. Comme le veut le protocole, l'ensemble des personnalités qui doivent intervenir envoient au préalable leur texte au préfet, qui le fait suivre à l'Élysée, car " toutes les allocutions doivent être soumises au président ${ }^{61}$ ». Il est ainsi possible pour les services de l'État de préparer une réponse adaptée aux problèmes locaux évoqués mais aussi d'exercer une surveillance de la parole des élus.

Le premier thème, récurent dans les discours des élus locaux est de remercier le chef de l'État d'être venu jusqu'à eux. À Châteauneuf-du-Faou, le conseiller général, Louis Dubuisson, évoque l'honneur que constitue pour tous le simple fait qu'il soit venu " visiter ce pays perdu dans la montagne Noire ". À Pleyben, le député-maire souligne la première historique que représente la visite de Félix Faure : "Jamais duc de Bretagne, roi ni empereur de France, jamais président de la République ne nous a honorés de sa visite ${ }^{62}$. "Ainsi, le simple fait de venir était vécu comme un hommage de la République à ces territoires ruraux à l'écart des grands centres urbains.

Le deuxième thème est l'affirmation que le président se trouve en terre républicaine et devant des républicains. Louis Dubuisson le souligne clairement : "Nous sommes ici profondément dévoués à la République et nous en donnons la preuve à chaque élection nouvelle ${ }^{63}$. „ De plus, celui qui parle donne des gages de républicanisme, précisant qu'il est " un républicain de la veille et, comme tel, victime de l'ordre moral ". Il y a aussi un appel à l'union républicaine. À Pleyben, cette communion s'incarne physiquement par le rassemblement, sur la place devant la mairie, des maires, adjoints, et conseillers municipaux des dix communes du canton afin qu'ils soient présentés au président. Elle passe aussi par la venue " en foule de nos habitants qui ont quitté le travail de la moisson et oublié les divisions de la politique ${ }^{64}$ " pour venir acclamer Félix Faure et ses ministres ainsi que les sénateurs et députés du Finistère. Au-delà des clivages et des enjeux politiques, la visite a donc pour effet de reformer le pacte républicain au village à travers des rites politiques consensuels qui sont omniprésents.

Pour certains, cette démonstration d'union autour du régime est insuffisante. Des élus, comme le député-maire de Pleyben, entendent souligner la force de l'attachement au pays. Pour cela, il convoque les ancêtres gaulois. Ainsi dit-il à Félix Faure que, du haut du clocher, le président

61. Arch. dép. du Finistère, 1 M 317, télégramme du préfet du Finistère au préfet des Côtes-du-Nord, 8 août 1896.

62. Arch. mun. de Pleyben, discours du maire devant Félix Faure, 30 août 1896

63. Le Finistère, 11 août 1896.

64. Arch. mun. de Pleyben, discours du maire, 30 août 1896. 
Figure 6 - Le président au village ne se limite pas aux réceptions officielles et se livre à un bain de foule devant le calvaire de Pleyben

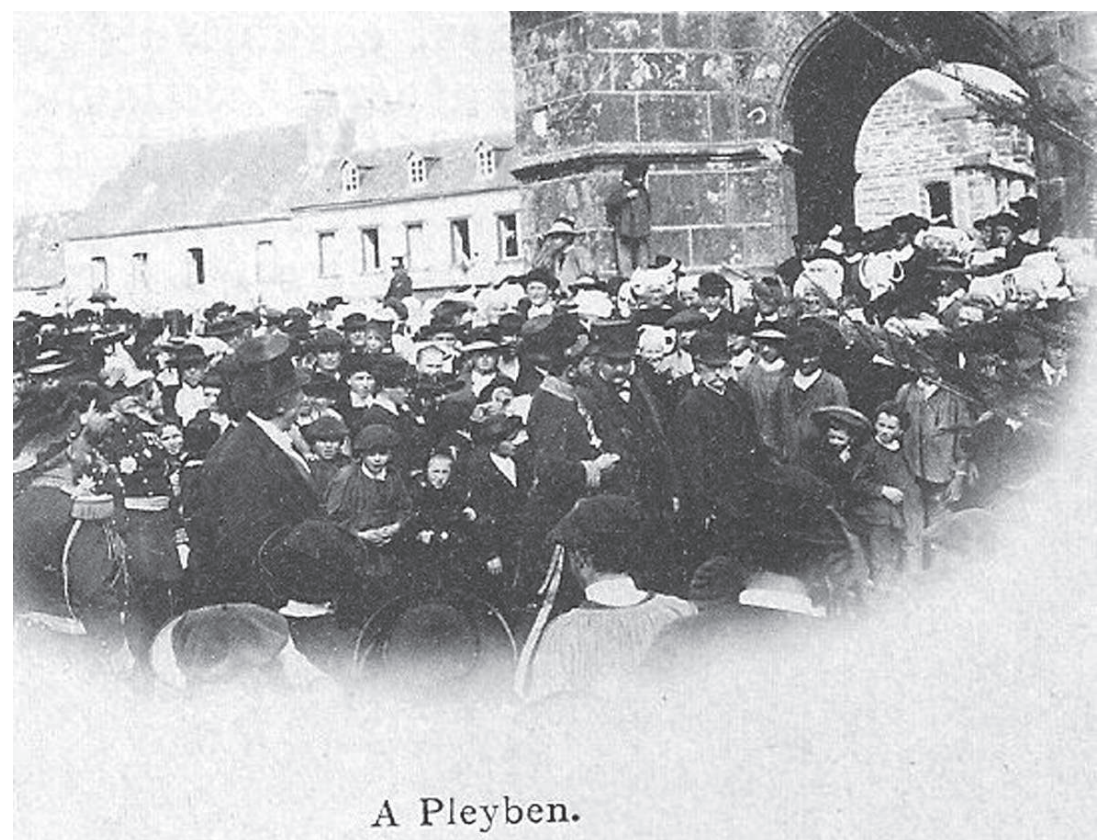

pourrait contempler " au nord, les montagnes d'Arrée où habitent des hommes bruns aux yeux noirs. Ce sont des Celtes. Et au sud, les montagnes Noires, où les hommes sont grands et blonds, aux yeux bleus : ce sont des Gaulois. "Les Gaulois étaient blonds" a écrit César. Celtes et Gaulois ne font aujourd'hui qu'une famille comme les Français et les Bretons ne forment qu'une nation ${ }^{65}$ ". L'histoire locale se veut ici l'illustration de l'histoire nationale et montre, du même coup, que la petite patrie est bien une composante de la " mosaïque merveilleuse ${ }^{66}$ " française. La France de 1896 prolongerait donc ainsi une très ancienne "nation gauloise ". Les habitants du canton avec leurs traits physiques identifiables, issus directement du Moyen Âge, pourraient incarner, comme un modèle, à leur échelle, la fusion des peuples des périphéries au sein d'une même nation. Sous la III République, l'identité nationale est un amalgame du national et du local, ici incarné par cette communauté d'ancêtres convoqués par le maire de Pleyben.

La République, abstraite, est incarnée avec la présence du président au village. Elle descend vers les masses paysannes (Maurice Agulhon) avec

65. Arch. mun. de Pleyben, discours du maire, 30 août 1896.

66. THIEsse, Anne-Marie, Ils apprenaient la France, l'exaltation des régions dans le discours patriotique, Paris, Éditions de la Maison des sciences de l'homme, 1997, p. 3. 
la force du décorum et la mise en scène du pouvoir républicain. Car Félix Faure est accompagné de Jules Méline, Président du Conseil et ministre de l'agriculture, de Jean-Baptiste Darlan à la justice (et à l'intérieur par intérim), des membres de l'Élysée, des parlementaires du département. Devant ces gens au pouvoir, c'est une occasion " historique " de solliciter des interventions politiques sur des dossiers qui touchent à la vie locale.

Le sujet le plus important est le désenclavement par le train. Cette partie du centre Finistère est marquée par l'isolement et par le manque de moyens de déplacement et de transport modernes. Depuis près de vingt ans, les élus locaux demandent la mise en place d'une ligne de chemin de fer reliant Châteaulin à Carhaix qui, avec sa gare, est le pôle central du réseau breton depuis 1888. Cette ligne promise depuis le 17 juillet 1879 concerne les deux chefs-lieux de canton, Châteauneuf-du-Faou et Pleyben : en 1896, les enquêtes sont bouclées, le conseil général a voté $300000 \mathrm{~F}$ pour acheter les terrains nécessaires à l'établissement de la voie, et enfin le projet de loi demandant la déclaration d'utilité publique de cette ligne a été déposé sur le bureau de la chambre des députés le 11 juillet 1896. Ce dossier touche à la vie économique de cette région agricole et la venue en personne du président de la République, accompagné du chef du gouvernement, offre l'occasion de demander publiquement de faire hâter le vote au Parlement.

Le maire de Châteauneuf-du-Faou associe fidélité au régime républicain et exigence de ligne de chemin de fer : "Vous trouverez légitime, j'en suis sûr, que je me fasse devant vous le respectueux interprète du vœu le plus ardent de mes concitoyens en appelant votre haute attention sur notre éloignement de toute voie ferrée. Cependant, depuis 1870, aucune région n'a donné plus de gages d'inébranlable attachement aux institutions républicaines; aussi attendons-nous, en retour, un prochain témoignage de la bienveillance du gouvernement et des Chambres qui ne voudront pas retarder plus longtemps la déclaration d'utilité publique du chemin de fer à voie étroite de Carhaix à Châteaulin ${ }^{67}$ ". Ainsi, les choses sont-elles dites clairement. Les élus, au nom de la population rassemblée, réclament maintenant leur dû. Le conseiller général enfonce ensuite le clou, devant Méline, en insistant sur l'impact qu'aurait cette ligne pour les intérêts agricoles dans " une région jusqu'à présent déshéritée ${ }^{68}$ ".

La situation agricole est l'autre sujet évoqué devant les représentants de l'État. Dans le contexte de la crise qui frappe le pays, les élus saisissent l'occasion qui leur est offerte de s'adresser au pouvoir. Il est d'ailleurs exceptionnel de pouvoir le faire au couple exécutif, réuni sur place ${ }^{69}$ : Félix Faure est ici accompagné par le Président du Conseil en personne. On peut donc penser que ce voyage au cour d'une Bretagne largement rurale et au contact des masses paysannes intéressait politiquement Jules Méline.

67. Le Finistère, 11 août 1896.

68. Ibidem.

69. Durant la III ${ }^{e}$ République, on ne relève qu'un seul autre exemple dans le Finistère avec Waldeck-Rousseau accompagnant Émile Loubet à Brest en 1902. 
Président du Conseil depuis avril 1896, il gère également le ministère de l'agriculture, " pièce essentielle de son dispositif politique ${ }^{70}$ ". Il lui semble alors prioritaire de renforcer le lien entre le monde paysan et le pouvoir républicain. Cela explique sa politique douanière et les mesures protectionnistes prises, quatre ans plus tôt, en faveur de l'agriculture. En 1896, il dirigeait un gouvernement modéré qui bénéficiait du soutien de la France des terroirs. Le maire de Châteauneuf-du-Faou termine son discours par un hommage à Jules Méline " qui doit se sentir ici entouré d'amis sincères; il n'est pas un paysan qui ne connaisse les éminents services qu'il a rendus à l'agriculture ${ }^{71}$ ». Ensuite, le conseiller général de Châteauneuf-du-Faou profite de l'occasion qui lui est ainsi donnée de pouvoir adresser une demande au gouvernement : "Tous dans le pays vivent de l'agriculture, ceux qui ne cultivent pas exercent des professions qui ne peuvent prospérer que si elles sont utiles aux agriculteurs. Ces cultivateurs qui vous entourent espèrent que, dans un prochain avenir, le gouvernement pourra diminuer les charges qui pèsent lourdement sur la terre, et principalement l'impôt foncier ${ }^{72}$. " À Châteaulin, une nouvelle preuve de la popularité de Méline dans le monde rural est donnée lorsque les maires du canton, après avoir été présentés au Président du Conseil, crient : "Vive Méline! Vive le père de l'agriculture ${ }^{73}$ ! "

Le dernier grand thème relevé dans les discours touche à l'œuvre scolaire. Le maire de Pleyben détaille son action dans ce domaine : "Nos écoles sont belles et prospères. Il y a vingt-cinq ans, la commune de Pleyben avait un instituteur et une institutrice, avec 100 à 150 élèves. Aujourd'hui nous avons, dans notre commune, cinq écoles de garçons et cinq écoles de filles, avec douze instituteurs, onze institutrices, et près de mille élèves ${ }^{74}$. " Le résultat est impressionnant pour une commune de 3661 habitants. En prenant 1871 , année fondatrice, comme date repère, l'élu fait de ce bilan une réussite républicaine.

L'accès à la parole est l'apanage des élus locaux, maires et conseillers généraux. Dans ce Finistère intérieur et rural, ce sont comme en ville, les notables issus de la bourgeoisie qui reçoivent le président : négociants et médecins, illustration de la réussite sociale républicaine. Leur discours est centré sur l'adhésion au régime et sur la recherche du progrès grâce aux deux piliers représentés par le train et l'école publique. Ces divers intervenants incarnent l'accès aux responsabilités de nouvelles élites, ce qui brise du même coup l'image d'une population rurale dominée, encore et toujours, par la vieille noblesse bretonne, même si cela reste vrai dans d'autres parties de la Bretagne ${ }^{75}$.

70. DÉmIER, Francis, La France du XIX siècle (1814-1914), Paris, Le Seuil, coll. " PointsHistoire ", 2000, p. 361.

71. Le Finistère, 11 août 1896.

72. La dépêche de Brest, 13 août 1896.

73. Le Finistère, 11 août 1896.

74. Ibidem.

75. BENSOUSSAN, David, «L'influence socio-politique de la noblesse dans les campagnes

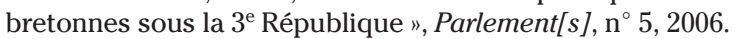


À côté de ces élus locaux, on entend le premier vicaire de Châteauneufdu-Faou, l'abbé Souêtre, « un gars superbe, une manière de démon en sou$\operatorname{tane}^{76}$ ", présenter le clergé du canton puis déclarer au président :

"Chargé de représenter M. le curé, retenu par la maladie, je me fais un devoir de m'unir aux autorités municipales pour vous souhaiter la bienvenue et vous remercier du grand honneur de votre visite. Je suis heureux de vous offrir, comme au représentant du pouvoir, les hommages respectueux et dévoués du clergé. Prêtres, nous n'avons en vue que les intérêts religieux qui nous sont confiés et nous associons dans un même culte l'amour de Dieu et de la patrie. Aussi permettez-moi de dire : Vive Dieu! Vive la France! Vive le président ${ }^{77}$ !"

Le Finistère ne publie pas ce texte mais fait paraître en revanche la réponse présidentielle : " Je suis très touché, monsieur le vicaire, de la déclaration que vous venez de me faire en l'absence du curé-doyen, dont je regrette la maladie. Je ne doute pas de vos bons sentiments et j'espère bien que vous êtes dévoués à l'ordre des choses établi et soucieux de l'observation des lois concordataires ${ }^{78}$. " La réponse de Félix Faure qui paraît dans la presse catholique diffère de celle-ci pour la dernière phrase : " J'aime à croire que tout en gardant vos opinions personnelles, vous respectez le régime établi et vous vous soumettez aux lois concordataires ${ }^{79}$. " La polémique, entre républicains et catholiques, naît alors de cette intervention perçue par les premiers comme une leçon et un rappel au concordat. De plus, le prêtre ne crie pas " Vive la République! ", ce qui n'est étrangement relevé que par la presse nationale ${ }^{80}$ et ne vient pas alimenter la polémique locale. À cela, s'ajoute la question : l'absence du curé-doyen est-elle due à une maladie diplomatique?

\section{L'enthousiasme des foules: \\ “Vive an aotrou president! Vive monsieur le Président ${ }^{81}$ ! »}

On peut penser que le loyalisme à la République se mesure aux efforts fournis pour assurer une toilette républicaine à la cité visitée. Il se mesure certainement aussi à la participation populaire et à ses manifestations de sympathie. Pour que la visite soit réussie, la population, mobilisée par les maires, doit jouer le rôle qui lui est attribué dans le dispositif officiel, être présente et acclamer le passage de Félix Faure.

À Morlaix, par exemple, "Tout le monde cherche d'abord à voir, puis les acclamations retentissent : Vive le Président! Vive Félix Faure! Et quelques cris de Vive la République ${ }^{82}$. " À cet accueil, le président répond

76. Le journal des débats, 10 août 1896.

77. La Résistance, 22 août 1896.

78. Le Finistère, 11 août 1896

79. La Résistance, 22 août 1896.

80. Le journal des débats, 10 août 1896.

81. Gers, Paul et Belon, Paul, Les Voyages..., op. cit. p. 17.

82. La Résistance, 11 août 1896. 
par des saluts puis se plie au protocole et remet des décorations. Ceci terminé, il s'affranchit de la présentation des notables du canton initialement au programme, et se lance dans un bain de foule accompagné du maire de Morlaix et des personnalités du cortège. Ce rapprochement physique se veut aussi symbolique : le président vient se montrer aux citoyens et il entend ne pas être maintenu à distance de ces gens qui sont venus le voir. Le décorum et le protocole éloignent; le bain de foule est créateur d'émotion et de joie comme le souligne même la presse catholique qui n'aime pas beaucoup ce président franc-maçon : "Cette preuve de confiance et de simplicité ravit le peuple, comme les paroles aimables dites aux uns et aux autres, comme les sourires adressés à tous. Les cris de Vive le Président! Vive Félix Faure éclatent de plus en plus chaleureux ${ }^{83}$." Évidemment, cette plongée improvisée du chef de l'État provoque les acclamations des spectateurs désormais aux premières loges et pouvant, pour quelques chanceux, parler et serrer la main de l'acteur principal du spectacle présidentiel.

Dans les petites communes visitées, la proximité est de mise. Après avoir sacrifié au rituel d'accueil et d'échange des discours, c'est l'occasion d'approcher le président. À Châteauneuf-du-Faou, lors du vin d'honneur, " le président se mêle familièrement à la foule des conseillers municipaux, des fonctionnaires et des invités. Le spectacle est alors d'une animation charmante. Mais hélas! il dure peu. Le moment du départ est arrivé! Il faut remonter en voiture ${ }^{84}$ ". À Châteaulin, le président fait reculer l'escorte de gendarmes pour être plus au contact de la population et s'adresse aux gens. Ce rapport de proximité par le contact direct avec les personnes venues le voir et avec les élus et ces fonctionnaires qui assurent de nouvelles missions dans les chefs lieux de cantons, renforce l'idée d'une rencontre entre le terrain et le centre politique et administratif. Le président vient au contact, au village, et c'est la République qui vient aux citoyens.

Afin de montrer l'adhésion populaire, avant et après le passage présidentiel, les élus, sur une idée sans doute initiée par l'Élysée ${ }^{85}$, suscitent l'organisation d'un cortège de cavaliers qui se joindraient à l'escorte militaire. Le 8 août, cette escorte paysanne est moins nombreuse qu'escomptée et c'est " deux ou trois douzaines [de cavaliers] au lieu des centaines qui étaient annoncés ${ }^{86}$ " qui accompagnent le président sur les routes du centre Finistère. Si l'objectif réel était bien d'avoir plusieurs centaines de cavaliers, cela relevait d'une grande ambition, difficile à atteindre. Si l'on suit les journalistes, la raison de ce manque est moins à chercher du côté d'une réticence populaire que du côté des conditions météorologiques :

83. Ibidem.

84. La Dépêche de Brest, 13 août 1896.

85. Arch. mun. de Châteaulin, 19 juillet 1896, lettre du commandant Moreau au maire : "Le Président sera enchanté d'être escorté le long de la route par des hommes du pays en costume."

86. Le Finistère, 11 août 1896. 
" La pluie tombe à flots par instant et couvre de son linceul gris l'admirable paysage. Elle a dû effrayer aussi beaucoup de nos cavaliers bretons ${ }^{87}$."

Figure 7 - Le cortège présidentiel encadré par les cavaliers de l'armée, voiture découverte sous la pluie, entre Carhaix et Châteaulin

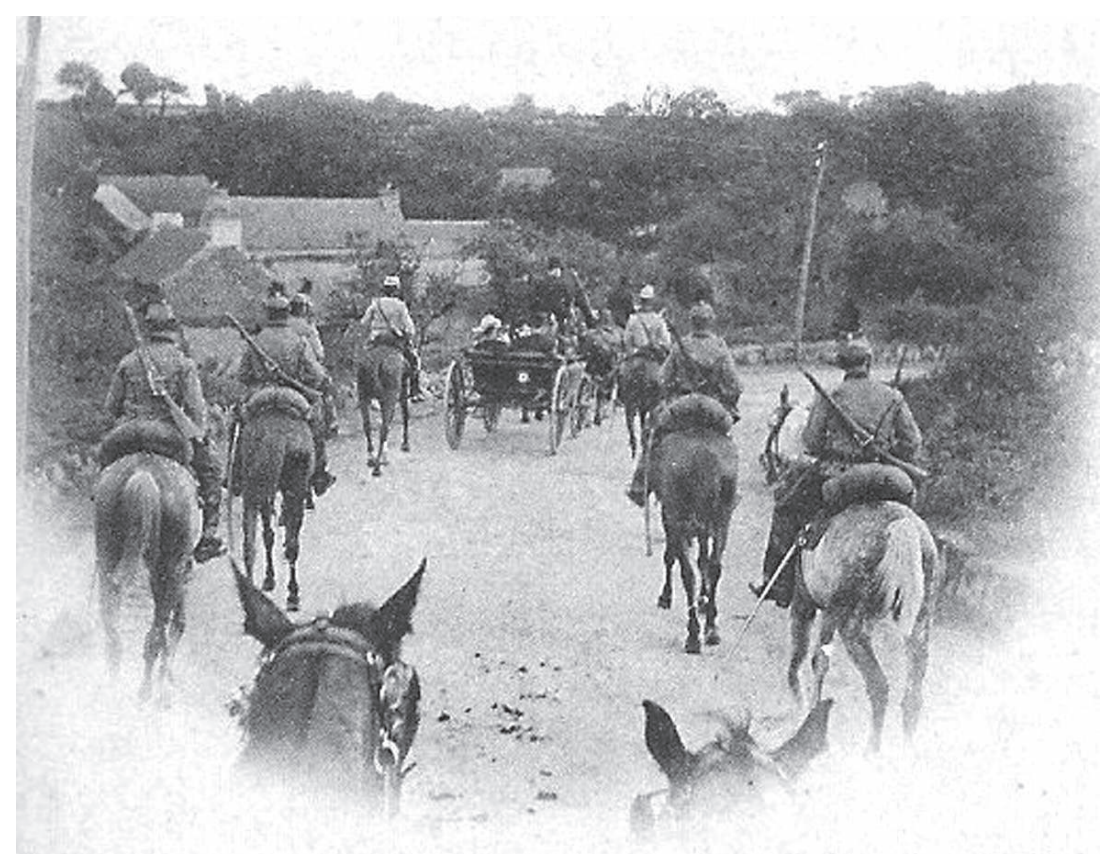

De Carhaix à Châteaulin.

En tous les cas, la pluie ne gêne pas le président. Sur 25 km, entre Carhaix et Châteauneuf-du-Faou, Félix Faure se trouve " sous une pluie battante que le président reçoit stoïquement dans son landau découvert ${ }^{88}$ ". Le chroniqueur officiel valorise l'attitude présidentielle qui fait apparaître un chef de l'État insensible aux aléas climatiques. Au-delà de l'anecdote, il s'agit de montrer de manière ostensible aux spectateurs son refus d'une protection contre la pluie afin de se placer sur un semblant d'égalité avec eux. Le journaliste du Figaro confirme : "Comme il y a des Bretons tout le long de la route, M. Faure ne veut pas qu'on ferme sa voiture; il n'a point de pardessus; on lui en prête un, mais sous son chapeau qu'il retire tout mouillé chaque fois qu'il aperçoit un groupe, il ne tarde pas à avoir une attitude extraordinaire ${ }^{89}$. "En somme, le message est : ils sont venus nous

87. Ibidem.

88. Gers, Paul et Belon, Paul, Les Voyages..., op. cit. p. 19.

89. Le Figaro, 9 août 1896. 
voir, ils sont mouillés, soyons mouillés. Car ici, comme souvent, c'est l'ensemble du cortège officiel qui doit rester en voitures découvertes. Refuser de fermer le landau ou un parapluie est bien un acte politique qui vise à rapprocher le président des citoyens, c'est ce qu'Alain Corbin a appelé "l'effet pluie ${ }^{90}$ ".

Sans doute la phase préparatoire de décoration de la commune et d'organisation de la fête contribue-t-elle à impliquer les gens. Il s'agit maintenant d'être à la hauteur de l'événement et de montrer aux représentants les plus éminents de la République que le village s'est mobilisé pour les saluer. La participation est un réel enjeu pour les maires. Celui de Carhaix lance un appel à tous les habitants du canton, prenant le parti de croire qu'ils seront heureux de suspendre leurs travaux pour venir saluer le président. À Pleyben, la population est « invitée à venir en foule au bourg, en habits de fête, pour témoigner au président sa satisfaction que leur causait sa visite à travers le département ${ }^{91}$ ". Le salut au président peut se faire le long des routes et dans le chef-lieu de canton où a lieu la cérémonie d'accueil et où on espère assez de monde pour avoir un " effet foule ". Mais les maires de Pleyben ou de Carhaix ne lancent pas un appel politique explicite de soutien au régime républicain.

\section{Figure 8 - Le travail est suspendu ce jour de visite présidentielle : la population est au rendez-vous même dans les petits hameaux}

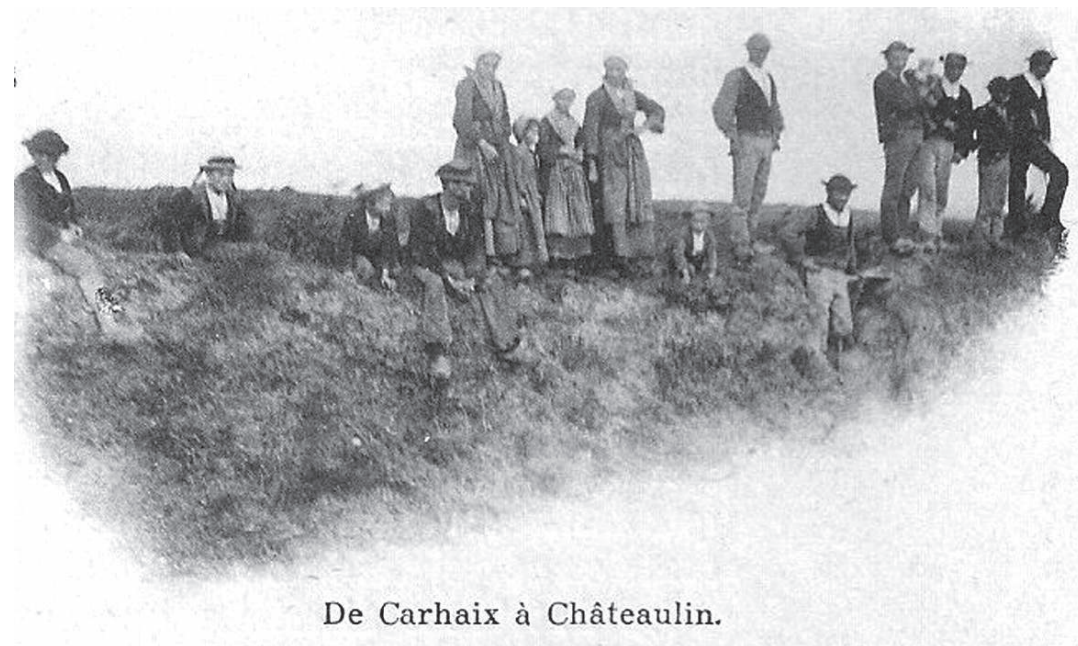

90. CoRbIn, Alain et VEIGA, Nathalie, « Le monarque sous la pluie : les voyages de LouisPhilippe I ${ }^{e r}$ en province (1831-1833) ", La terre et la Cité, mélanges offerts à Philippe Vigier, Paris, Créaphis, 1994, p. 223.

91. Arch. mun. de Pleyben, délibération du conseil municipal, 30 août 1896. 
De Carhaix à Châteauneuf-du-Faou, le cortège est honoré par le monde paysan. Dans ce paysage de bocage ${ }^{92}$ et du fait de ses caractéristiques (lacis de chemins, talus, atomisation du peuplement, difficultés de circulation), ceux qui ne se sont pas rendus au bourg attendent près de chez eux ou de leurs champs : "Dans le voisinage de chaque ferme on aperçoit, juchés sur les hauts talus de la route, des groupes de paysans, hommes et femmes, qui se découvrent respectueusement et regardent de tous leurs yeux. Parfois ce sont de petits pâtres, accourus du fond d'une lande, qui viennent tirer leurs bonnets au passage du chef de l'État. Nous serions surpris si ces hommages naïfs n'étaient pas de ceux qui ont le mieux trouvé le chemin de son cœur ${ }^{93}$. "L'arrivée de Félix Faure qui est vécue comme un véritable événement au village l'est davantage encore à l'échelle des hameaux, où la population s'est massée pour assister ensemble au passage du cortège : "Sur les routes, de vieux et bons campagnards [ont] un instant quitté leur travail pour venir voir un spectacle qu'ils n'ont jamais rêvé [...], puis des vieilles, surprises par ce cortège qu'elles attendaient cependant, mais qui les éblouit néanmoins au passage [...] et qui ne sachant comment manifester leur joie, s'agenouillent et se signent [...] n'est-ce pas que c'est attendrissant ${ }^{94}$ ?"

Il y a là une manifestation de communion républicaine mâtinée sans doute de pure curiosité pour ces personnes bien éloignées socialement de ces gens qui passent. D'ailleurs, l'hommage rendu par les paysans ne peut être que " naïf ». Ce terme est relevé dans Le Finistère, mais aussi dans l'ouvrage des chroniqueurs officiels Paul Gers et Paul Belon, lorsqu'ils décrivent l'ornementation des villages avec « les maisons décorées de feuillage, ornées de tentures où, dans un langage naïf, les habitants disaient le cri de leur cœur ${ }^{95}$ ". Cette naïveté supposée imposerait la bienveillance comme celle d'un père sur ses enfants et comme celle du colonisateur sur l'indigène. Mais ce regard posé sur ces populations par les journalistes n'est-il pas plus simplement celui d'urbains sur des ruraux?

À Châteauneuf-du-Faou, qui a fourni de nombreux vivats enthousiastes, "Vive le président! Vive Félix Faure! ", il y a une sorte de réciprocité lorsque " de quelques-unes des voitures de la suite présidentielle on crie : vive Châteauneuf ${ }^{96}$ ! " Ainsi, la communion républicaine serait-elle totale. Mais à qui s'adressent ces acclamations populaires? Pour les républicains, les applaudissements saluent, au-delà de l'homme, le régime républicain. C'est le sens que veut donner le président à ces acclamations lorsqu'il déclare qu'il " connaît les sentiments républicains de la population châteauneuvienne $^{97}$ ". Du côté des conservateurs, il reste difficile de reconnaître l'ad-

92. LE GALL, Laurent, “ La Seconde République au bocage. Finistère (1848-1852) ", Annales de Bretagne et des Pays de l'Ouest, t. 113, 2006.

93. Le Finistère, 11 août 1896.

94. Gers, Paul et Belon, Paul, Les Voyages..., op. cit. p. 17.

95. Ibidem, p. 16.

96. La Dépêche de Brest, 13 août 1896.

97. Ibidem. 
hésion des Bretons à ce régime. La catholique Résistance propose ainsi d'expliquer la chaleur de l'accueil par la sympathie de l'homme et non par l'appel de la République : " La bonne grâce et l'affabilité de M. Félix Faure ont vite triomphé partout de la réserve première de la foule et provoqué des acclamations qui s'adressaient surtout à sa personne ${ }^{98}$. " L'appel à participer semble avoir été entendu. À Pleyben, c'est la satisfaction qui domine et les élus notent que les gens sont venus "des moindres hameaux " en dépit du mauvais temps. Cet enthousiasme des foules a la vertu d'être revigorant. C'est ce que dit le président à un vieil ami, secrétaire du syndicat de la tannerie du Finistère, venu le voir à Carhaix; alors qu'il l'interroge sur les fatigues du voyage, Félix Faure répond que " l'accueil chaleureux des populations bretonnes ${ }^{99}$ " les lui faisait oublier.

\section{L'expérience scientifique de Félix Faure}

Cette visite dans le centre Bretagne était présentée par certains journaux comme un pari. Car l'enjeu était réel : si les fêtes données dans les grandes villes sont synonymes d'éclat et de faste républicains, qu'en seraitil en milieu rural dans ces petites communes sans grandes ressources? « Il restait à savoir ce qu'il trouverait en pénétrant au cœur de la Bretagne, parmi ces populations que les fêtes officielles n'ont pas gâtées. La tentative a pu paraître téméraire. Eh bien! L'on peut dire aujourd'hui que le résultat lui a donné raison ${ }^{100}$. " Ce voyage était même perçu par certains journalistes parisiens comme une sorte d'expérience scientifique lors de laquelle les formes de la participation populaire seraient le révélateur de sa réussite. L'accueil des populations est venu souligner la réussite de cette journée. Pour la presse républicaine, ce voyage " aura montré une Bretagne que nous ne connaissions pas encore [...] en communion intime désormais avec la République qu'elle ne sépare plus de la patrie ${ }^{101}$ ". C'est aussi un monde rural avide de progrès, montrant son acceptation du régime à travers le décorum républicain, mis en place et financé par lui-même, que découvre le président dans ces villages du Finistère intérieur. Au total, cette plongée présidentielle au village, et l'écho qui lui fut donné, furent une manière de montrer au pays l'intégration des Bretons et de la Bretagne au sein de l'espace national; intégration qui ne fut réellement définitive qu'au sortir de la Grande Guerre. Pour l'heure, ce "moment républicain " avait contribué à fabriquer du lien politique grâce à la rencontre entre le peuple, les élites et la République, sur fond de binious jouant La Marseillaise.

98. La Résistance, 15 août 1896.

99. La Dépêche de Brest, 9 août 1896.

100. Le Finistère, 11 août 1896.

101. La République française, 10 août 1896. 


\section{RÉSUMÉ}

La Bretagne resta longtemps une terra incognita pour les chefs d'Etat. Avec la République, la rareté des voyages officiels resta une permanence. C'est pourquoi la visite de Félix Faure en 1896, vingt-deux ans après celle du maréchal-président Mac Mahon, fut en soit un événement. Premier président républicain à parcourir la péninsule armoricaine, il organisa la rencontre improbable entre le peuple breton, les élites républicaines et la République elle-même, sur fond de binious jouant La Marseillaise. Félix Faure plongea au cœur de cette Bretagne bretonnante perçue comme un conservatoire du pittoresque et de l'exotique. Dans ces petits villages où ni duc, ni roi, ni empereur ne vinrent jamais, les maires mobilisèrent largement pour que la fête républicaine soit à la hauteur. Appliquant un protocole valorisant le pouvoir, les élus locaux montrèrent leur attachement au régime tout en explicitant leurs doléances. Lors des cérémonies, les maires soulignèrent l'ancienneté de leur sentiment républicain tout en honorant tel "vieux républicain " de 1848. Pour les visiteurs, cette journée fut l'occasion d'une rencontre avec la bretonnité et la ruralité au sein d'un monde paysan choyé par le président du Conseil, Jules Méline, acclamé aux côtés de Félix Faure. Cette visite présidentielle au village apparaît être un exemple de " moment républicain " travaillant conjointement à la politisation des campagnes et à l'intégration de cette périphérie bretonne à l'espace national.

\section{ABSTRACT}

For a long time, Brittany remained a "terra incognita" for Heads of State. Despite the advent of the Republic, official trips were still rare. That is why Felix Faure's visit in 1896, 22 years after President-Marshal Mac Mahon's, was a real event in itself. He was the first republican president to travel through the Armorican Peninsula, and he organized an unlikely meeting between the Breton people, republican elites and the Republic itself, with, in the background, bagpipes playing the Marseillaise. Felix Faure immersed himself into the heart of this Breton-speaking Brittany, which was considered as a repository of picturesqueness and exoticism. In those small villages, where no duke, king or emperor ever came, the mayors widely mobilized the inhabitants, in order to have an imposing republican celebration. Using a protocol enhancing the value of the republican government, local councillors showed their attachment to the system while, at the same time, making their grievances clear. During the ceremonies, the mayors, while honouring a special "old republican" of 1848, underlined the fact that their republican feeling was an ancient one. As for the visitors, this memorable day gave them the opportunity to become aware of the Breton feeling and of country life inside a peasant world dear to Prime Minister Jules Méline, who was warmly greeted, along with Felix Faure. This presidential visit to the village seems to be an example of a "republican moment", the aim of which was both to bring politics to the country and to integrate peripheral Brittany into the nation. 